\title{
ESCOMPTE experiment: intercomparison of four aircraft dynamical, thermodynamical, radiation and chemical measurements
}

\author{
F. Saï ${ }^{a, *}$, U. Corsmeier ${ }^{b}$, N. Kalthoff ${ }^{b}$, C. Kottmeier ${ }^{c}$, M. Lothon ${ }^{a}$, \\ A. Wieser ${ }^{b}$, T. Hofherr ${ }^{b}$, P. Perros ${ }^{c}$

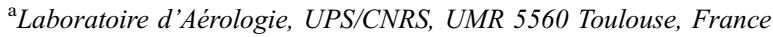 \\ ${ }^{\mathrm{b}}$ Institut für Meteorologie und Klimaforschung, Forschungszentrum Karlsruhe/Universität Karlsruhe, \\ Karlsruhe, Germany \\ ${ }^{\mathrm{c}}$ Laboratoire Inter-Universitaire des Systèmes Atmosphériques, \\ Université de Paris XII, UMR 7583, Créteil, France
}

\begin{abstract}
Among seven airplanes involved in the Experience sur Site pour COntraindre les Modèles de Pollution atmosphérique et de Transport d'Emission (ESCOMPTE) experiment in 2001, four measured classical meteorological parameters, radiation fluxes, trace gases and turbulence (for three among four): the Dornier 128 from the Institut für Meteorologie und Klimaforschung, the Fokker 27 ARAT from the Institut National des Sciences de l'Univers, the Merlin 4 and Piper Aztec 23 from Météo France. This paper presents the results of intercomparison flights between three pairs of aircraft. The results are very similar for mean parameters except for the horizontal wind measurements provided by the Merlin that showed a problem that is probably linked to the measurement of the aircraft velocity. Further investigation is required to know whether corrections are possible or not for these wind measurements. Turbulence is studied along two legs over a flat and homogeneous area: in spite of the heterogeneity of the measured functions (one leg is close to the top of the boundary layer), the comparison is rather good. The relative accuracy of the data provided to the data base is given. It easily allows to use the huge amount of aircraft data collected during the experiment with very few restrictions. We underline some points where efforts should be borne for
\end{abstract}

\footnotetext{
* Corresponding author.

E-mail address: saif@aero.obs-mip.fr (F. Said).
} 
future experiments: wind coupling between Inertial Navigation System data and Global Positioning System (GPS) data, $\mathrm{CO}$ and $\mathrm{NO}_{x}$ measurements.

Keywords: Aircraft chemical measurements; ESCOMPTE; Aircraft wind measurements; Atmospheric turbulence

\section{Introduction}

Experience sur Site pour COntraindre les Modèles de Pollution atmosphérique et de Transport d'Emission (ESCOMPTE) is a program aimed to study atmospheric pollution. The objectives of the program, the details of the experimental set-up and the strategy are described in the work of Cros et al. (2004). The program has been implemented to constitute an extremely detailed data base to contribute to the development and validation of models likely to forecast polluted episodes. Among the numerous means deployed during the experiment observing period, three to seven airplanes flew either separately or in small formation, to obtain an accurate temporal and spatial documentation, likely to capture both the 2D extent of the polluted plume and the low troposphere vertical stratification. A typical Intensive Observation Period day included one to three flights, possibly repeated three times a day, i.e. in the early morning (5:00-7:30 UTC); in the middle of the day (9:00-12:30 UTC) or in the afternoon (after 13:00 UTC). Flight plans are described by Cros et al. (2004). Usually, one aircraft explored the upstream boundary conditions by flying superposed legs in a vertical plane. One or two other airplanes described the $2 \mathrm{D}$ structure of the low troposphere by flying parallel legs at constant level, inside the atmospheric boundary-layer or/and just over. Some flights were occasionally replaced by specific operations, aiming at studying the sea-breeze structure, the effect of the Marseille city or the penetration of the wind inside the valleys. The total amount of flight hours reaches $309 \mathrm{~h}$ (125 flights). The distribution between the various aircraft is indicated in Table 1.

As a matter of fact, most experiments involving several airplanes require the comparison of the measurements since there is no absolute means for comparing inflight measurements. Similar comparisons were performed during FIFE (MacPherson et al., 1992), EUCREX (Quante et al., 1996) or BOREAS (Dobosy et al., 1997) for instance. The Merlin was previously compared to other airplanes during EUCREX (Quante et al., 1996) and to the ARAT during SEMAPHORE (Lambert and Durand, 1998); the Dornier during EFEDA (Grunwald et al., 1998), BERLIOZ (Corsmeier et al., 2002) and EVA (Kalthoff et al., 2002).

During ESCOMPTE, four airplanes among the seven measured similar parameters (Table 1) which imposes the necessity to compare with accuracy their respective measurements with the triple objective: (i) detect possible defects and try to correct them (this had to be done during the experiment); (ii) highlight differences and possibly propose slight corrections (to be applied after the experiment); (iii) estimate confidence levels for the archived data in the data base. An additional aim for this paper is to point out what 
Table 1

List of aircraft measurements performed and organizations operating the aircraft

\begin{tabular}{|c|c|c|c|c|}
\hline Aircraft & Measurements & Organization & $\begin{array}{l}\text { Number } \\
\text { of flights }\end{array}$ & $\begin{array}{l}\text { Flight } \\
\text { hours }\end{array}$ \\
\hline $\begin{array}{l}\text { Fokker } 27 \\
\text { ARAT }\end{array}$ & $\begin{array}{l}\text { Dynamics } \\
\text { Thermodynamics } \\
\text { Chemistry } \\
\text { Radiative fluxes } \\
\text { Turbulence }\end{array}$ & $\begin{array}{l}\text { INSU: Institut National des } \\
\text { Sciences de l'Univers }\end{array}$ & 27 & 67 \\
\hline Dornier 128 & $\begin{array}{l}\text { Dynamics } \\
\text { Thermodynamics } \\
\text { Chemistry } \\
\text { Radiative fluxes } \\
\text { Turbulence }\end{array}$ & $\begin{array}{l}\text { IMK: Institut für Meteorologie } \\
\text { und Klimaforschung }\end{array}$ & 15 & 49 \\
\hline Falcon 20 & Doppler lidar for wind & $\begin{array}{l}\text { DLR: Deutsche Forschungsanstalt } \\
\text { für Luft und Raumfarht }\end{array}$ & 11 & 27 \\
\hline Merlin IV & $\begin{array}{l}\text { Dynamics } \\
\text { Thermodynamics } \\
\text { Chemistry } \\
\text { Radiative fluxes } \\
\text { Turbulence }\end{array}$ & Météo France & 21 & 49 \\
\hline Piper Aztec 23 & $\begin{array}{l}\text { Dynamics } \\
\text { Thermodynamics } \\
\text { Chemistry }\end{array}$ & Météo France & 21 & 46 \\
\hline Piper Aztec 28 & Urban surface temperature & Private society & 8 & 17 \\
\hline ULM & $\begin{array}{l}\text { Dynamics } \\
\text { Thermodynamics } \\
\text { Chemistry } \\
\text { Radiative fluxes }\end{array}$ & $\begin{array}{l}\text { IFU: Institut für atmosphärische } \\
\text { Umweltforschung }\end{array}$ & 22 & 54 \\
\hline
\end{tabular}

Number of flights and hours flown per aircraft.

could be improved on the aircraft for future experiments. A new French aircraft (ATR42) is now being equipped to replace the ARAT and Merlin 4. The conclusions of this work could help for new developments.

After the description of the aircraft flights and equipment in Section 2, two sets of measurements will be used for intercomparison: (i) low frequency measurements (1 pt/s), described in Section 3. Corrections will be proposed from this study, according to the differences observed in the dynamical (wind), thermodynamical (pressure, temperature, and water vapor content), chemical (ozone, carbon monoxide and $\mathrm{NO}_{2}$ photodissociation coefficient into NO) and radiation (short and longwave radiations, surface temperature) parameters; (ii) turbulence measurements at computing rates of $25 \mathrm{~Hz}$ for Merlin and Dornier, $16 \mathrm{~Hz}$ for ARAT, described in Section 4. The Aztec was not equipped for turbulence measurements.

The weather conditions have been chosen to be cloud-free days with low wind speeds which corresponds to the most frequent situations encountered during the campaign. However, we have not been able to perform the intercomparison flights during the highly polluted situations and we will see it is a limitation for some chemical comparisons. 


\section{Aircraft flights and equipment description}

\subsection{Flight description}

Usually, intercomparison flights are flown in close formation. Either the pairs of aircraft are chosen according to the aircraft velocity so that the two airplanes may have relatively similar velocities: this enables them to fly at their optimum airspeed without modifying their angle of attack (MacPherson et al., 1992; Dobosy et al., 1997), or they all fly together with a 'wing-to-wing' configuration providing an accurate sampling of the same air-parcel (Quante et al., 1996) at a same common velocity.

For traffic control reasons, this kind of flight was not possible during ESCOMPTE except over the sea but chemical measurements required to fly over the ground to be able to measure the largest range of chemical species. Moreover, we made the choice to let the aircraft fly at their own velocity, to avoid the corrective maneuvers required to maintain the close formation. Our argument is that wind measurements are most of the time low during ESCOMPTE, and the agreement is always harder to reach under weak wind conditions. Furthermore, we prefer using the dynamical and thermodynamical sensors in the range for which the calibrations have been optimized. However, the drawback linked to this choice is that we never exactly sample the same air parcel, which can reveal a constraint in non homogeneous situations such as weak wind ones. This point is particularly crucial for turbulent measurements. The alternative solution would have been to increase the number of flight samples to be able to obtain some kind of statistics. The intercomparison flights were a compromise between trying to check many points about dynamics and chemistry and not spending too many hours for technical purpose only, because these flights could not be coupled to scientific missions. So it was considered that 15 flight hours spent for intercomparison was sufficient to validate the four airplanes and we used two legs (twice), for turbulence validation.

The intercomparison thus occurred by groups of two. The flights were spread over 2 days to be set in the middle of the day, at the moment when the diurnal cycle evolves the least. The flight times are described in Table 2. The three comparison flights, presented in Fig. 1, followed the same pattern which includes three phases:

- Vertical exploration: the aircraft fly in wing-to-wing formation. This enables them to analyse the same air parcel but they must avoid to pollute each other. To explore the widest range of thermodynamical parameters, the aircraft rise from $300 \mathrm{~m}$ to $3000 \mathrm{~m}$ on the A1-A2-A3 leg towards A4, then fly down along the same path, with a climb and sink rate of about $500 \mathrm{ft} / \mathrm{min}$. During the Dornier-ARAT flight, the upward

Table 2

Day and time of the comparison flights

\begin{tabular}{llr}
\hline & Day & \multicolumn{1}{c}{ UTC time } \\
\hline ARAT 50 DORNIER 15 & $01 / 07 / 07$ & 13.40 to 16.50 \\
AZTEC 25 DORNIER 14 & $01 / 07 / 07$ & 9.45 to 12.30 \\
ARAT 51 MERLIN 26 & $01 / 07 / 08$ & 11.10 to 13.40 \\
\hline
\end{tabular}

Flight number is specified. 

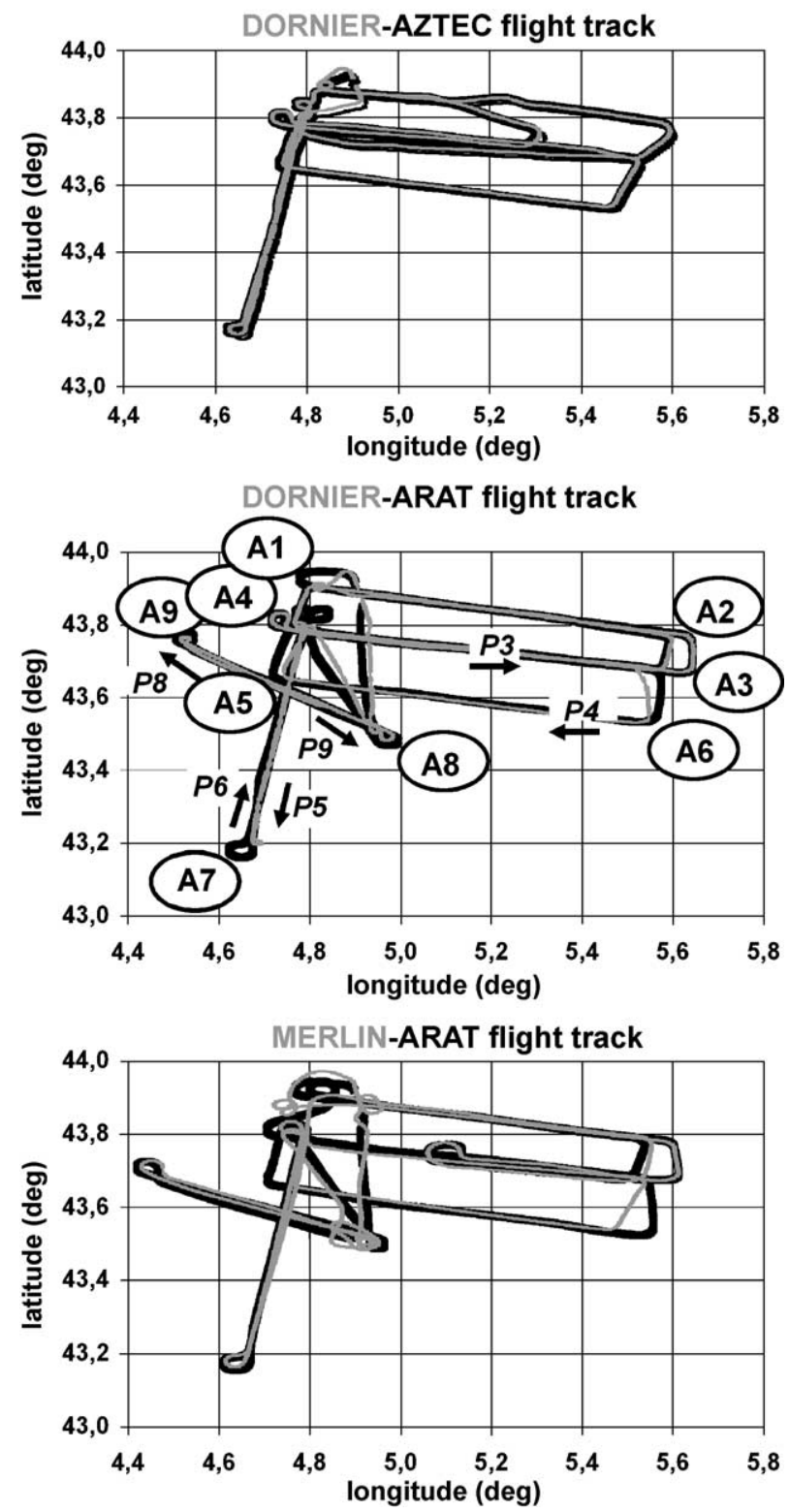

Fig. 1. Flight tracks for the three pairs of intercomparison flights from the GPS information. A1 to A9 are the turning points quoted in the text, $P 3$ to $P 9$, the flight leg numbers. The two northern legs are for the vertical ascent (ground to $3000 \mathrm{~m}$ ) and descent. Measurements levels are $800 \mathrm{~m}$ for P3, P4 and P5, $500 \mathrm{~m}$ for P6, $470 \mathrm{~m}$ for $\mathrm{P} 8$ and $150 \mathrm{~m}$ for $\mathrm{P} 9$.

sounding ended with a horizontal and stabilised leg at $3000 \mathrm{~m}$, and the downward one with one leg at $1000 \mathrm{~m}$, which explains that the flight tracks differ between diagrams A, B and C on Fig. 1: the Merlin-ARAT clamb down as soon as the ascent was 
Table 3

Sensor equipment on the four airplanes

\begin{tabular}{|c|c|c|}
\hline Parameter & Instrument/method & Unit \\
\hline \multicolumn{3}{|l|}{$A R A T$} \\
\hline \multirow[t]{3}{*}{ Geographic position: $\mathrm{X}, \mathrm{Y}, \mathrm{Z}$} & Sercel GPS: latitude, longitude and altitude (slow) & deg \\
\hline & $\begin{array}{l}\text { Sagem Uliss } 45 \text { INS: latitude and longitude } \\
\text { (slow and fast) }\end{array}$ & \\
\hline & TRT AHV12 Ground Altimeter & $\mathrm{m}$ \\
\hline \multirow[t]{2}{*}{ Aircraft attitude (fast) } & Roll, pitch, true heading angle & deg \\
\hline & Angular velocities: INS & $\operatorname{deg} \mathrm{s}^{-1}$ \\
\hline Pressure (fast) & $\begin{array}{l}\text { Static and differential pressure, attack and sideslip, } \\
\text { airspeed: five holes probe Rosemount } \\
1201 / 1221 \mathrm{~F} 1 / 1221 \mathrm{~F}\end{array}$ & $\mathrm{hPa}$ deg $\mathrm{ms}^{-1}$ \\
\hline Groundspeed $V_{x}, V_{y}, V_{z}$ (fast) & INS & $\mathrm{ms}^{-1}$ \\
\hline Wind $\mathrm{Ve}, \mathrm{Vn}, \mathrm{Vv}$ (fast) & five holes probe+ + INS & $\mathrm{ms}^{-1}$ \\
\hline Temperature (fast) & Rosemount E102AL, E102BW & ${ }^{\circ} \mathrm{C}$ \\
\hline \multirow[t]{2}{*}{ Humidity (slow) } & Dew Point Temperature: General Eastern 1011B & ${ }^{\circ} \mathrm{C}$ \\
\hline & Relative: Coreci 6100 , Hygrostor carbon plate & $\%$ \\
\hline Humidity (fast) & Lyman alpha AIR and ERC & $\mathrm{g} \mathrm{m}^{-3}$ \\
\hline Surface temperature & Barnes PRT5 & ${ }^{\circ} \mathrm{C}$ \\
\hline \multirow[t]{3}{*}{ Radiation VIS $\uparrow \downarrow$ IR $\uparrow \downarrow$} & Pyranometers, pyrgeometers Eppley & $\mathrm{Wm}^{-2}$ \\
\hline & PSP12913/PSP12370 & \\
\hline & Eppley PIR25695/PIR30605 & \\
\hline Ozone concentration (slow) & Thermo-Electron 49PS & ppbv \\
\hline $\begin{array}{l}\mathrm{NO}, \mathrm{NO}_{x}, \mathrm{NO}_{y}, \mathrm{PAN} \\
\mathrm{HNO}_{3} \text { (slow) }\end{array}$ & LISA MONA & ppbv \\
\hline $\mathrm{CO}$ & Thermo-Electron 48CTL & ppbv \\
\hline $\mathrm{NO}_{2}$ dissociation velocity & $J_{\mathrm{NO}_{2}} \uparrow \downarrow:$ Meteorologie Consult $946 / 950$ & $s^{-1}$ \\
\hline \multirow[t]{4}{*}{ Particles } & Backscattering coefficient: nephelometer MRI 1550B & $10^{-4} \mathrm{~m}^{-1}$ \\
\hline & Optical particles counter: TSI 3220-TSI 3010 & part $\mathrm{cm}^{-3}$ \\
\hline & PCASP activity coincidence & part \\
\hline & Black carbon:aethalometer PSAP & $\mu \mathrm{g} \mathrm{m} \mathrm{m}^{-3}$ \\
\hline $\mathrm{COV}$ & Canister sampling & \\
\hline \multicolumn{3}{|l|}{ DORNIER } \\
\hline \multirow[t]{2}{*}{ Geographic position: X, Y, Z } & $\begin{array}{l}\text { Novatel Differential GPS: latitude, longitude and altitude } \\
\text { Honeywell INS: latitude and longitude }\end{array}$ & deg \\
\hline & Optech 501 laser altimeter & $\mathrm{m}$ \\
\hline \multirow[t]{2}{*}{ Aircraft attitude (fast) } & Roll, pitch, true heading angle & $\operatorname{deg}$ \\
\hline & Angular velocities: INS & $\operatorname{deg~} \mathrm{s}^{-1}$ \\
\hline Pressure (fast) & $\begin{array}{l}\text { Static and differential pressure, attack and sideslip, } \\
\text { airspeed five holes probe, Rosemount } 1201,1221\end{array}$ & $\mathrm{hPa}$ deg $\mathrm{ms}^{-1}$ \\
\hline Groundspeed, accelerations & INS, GPS , both fast & $\mathrm{ms}^{-1}, \mathrm{~ms}^{-2}$ \\
\hline Wind Ve, Vn, Vv (fast) & five holes probe + GPS & $\mathrm{ms}^{-1}$ \\
\hline Temperature (slow) & Rosemount PT100 & ${ }^{\circ} \mathrm{C}$ \\
\hline Temperature (fast) & Open-wire Rosemount PT 100 & ${ }^{\circ} \mathrm{C}$ \\
\hline \multirow[t]{2}{*}{ Humidity (slow) } & Meteolabor dew point mirror & ${ }^{\circ} \mathrm{C}$ \\
\hline & Relative: Aerodata-Humicap & $\%$ \\
\hline Humidity (fast) & Lyman alpha & $\mathrm{g} \mathrm{m}^{-3}$ \\
\hline Surface temperature & KT19 sensor with scanner & ${ }^{\circ} \mathrm{C}$ \\
\hline Radiation VIS $\uparrow \downarrow$, IR $\uparrow \downarrow$ & Pyranometers, pyrgeometers Kipp and Zonen & $\mathrm{Wm}^{-2}$ \\
\hline Ozone concentration (slow) & Environment S.A. $\mathrm{O}_{3}-41 \mathrm{M}$ & ppbv \\
\hline Ozone concentration (fast) & Güsten & ppbv \\
\hline
\end{tabular}


Table 3 (continued)

\begin{tabular}{lll}
\hline Parameter & Instrument/method & Unit \\
\hline DORNIER & & ppbv \\
$\mathrm{NO}, \mathrm{NO}_{2}, \mathrm{NO}_{y}$, PAN (slow) & MetAir $\mathrm{NO}_{x} \mathrm{TO}_{y}$ SER20001 (modified) & ppbv \\
$\mathrm{CO}$ (slow) & Aerolaser AL5001 & ppm \\
$\mathrm{CO}_{2}$ (fast) & LI-COR 6252 & \\
Air sampling & Up to 30 canisters & \\
Surface reflectivity & Spectral linescanner (three channels) & \\
& Digital video camera &
\end{tabular}

MERLIN

Geographic position: X, Y, Z

Aircraft attitude (fast)

Pressure (fast)

Groundspeed

Wind Ve, Vn, Vv

Temperature (fast)

Humidity (slow)

Humidity (fast)

Surface temperature

Radiation VIS $\uparrow \downarrow$, IR $\uparrow \downarrow$

Ozone concentration (slow)

Ozone concentration (fast)

$\mathrm{NO}, \mathrm{NO}_{x}, \mathrm{NO}_{y}, \mathrm{PAN}$, $\mathrm{HNO}_{3}$ (slow)

$\mathrm{CO}$ (slow)

$\mathrm{NO}_{2}$ dissociation velocity

(slow)

COV

\section{PIPER AZTEC 23}

Geographic position:

X, Y, Z (slow)

Pressure (slow)

Groundspeed (slow)

Wind Ve, Vn, Vv (slow)

Temperature (fast)

Humidity (slow)

Ozone concentration (slow)

$\mathrm{NO}, \mathrm{NO}_{x}, \mathrm{NO}_{y}, \mathrm{PAN}$,

$\mathrm{HNO}_{3}$ (slow)
Trimble-VME Bancom BC635 GPS: latitude,

longitude and altitude (slow). Sagem Uliss 45

INS: latitude, longitude (fast)

Ground Altimeter TRT

Roll, pitch, true heading angle,

Angular velocities: INS

Static and differential pressure, attack and sideslip, airspeed: Sextant UMP40, Rosemount 1201, 1221F1, $1221 \mathrm{~F} 2+$ five holes probe

INS, GPS (slow)

Five holes probe + GPS (slow) or INS (fast)

Rosemount E102AL, E102BW, T4113

Dew Point Temperature: General Eastern 1011B

Relative: Coreci 6100

Lyman alpha AIR

Barnes PRT5

Pyranometers, pyrgeometers Eppley

PSP12913/PSP12370

Eppley PIR25695/PIR30605

Thermo-Electron 49C

Güsten

MetAir $\mathrm{NO}_{x} \mathrm{TO}_{y}$ SER2001

Thermo-Electron 48CTL

$J_{\mathrm{NO}_{2}} \uparrow \downarrow$ : Meteorologie Consult 946/950

Canister sampling

Trimble-VME Bancom BC635 GPS: latitude, longitude and altitude.

Ground Altimeter (5000' ) TRT

Static and dynamic pressure, attack and sideslip, airspeed: Rosemount 1221F1, 1221F2

GPS+Doppler radar

Doppler Dassault CINAB, GPS+five holes probe

Rosemount E102AL, Sfim T4113

Dew Point Temperature: Cambridge

Relative: Coreci

Environment S.A. $\mathrm{O}_{3}-41 \mathrm{M}$

MetAir $\mathrm{NO}_{x} \mathrm{TO}_{y}$ SER2001 deg

$\mathrm{m}$

deg

$\operatorname{deg} \mathrm{s}^{-1}$

$\mathrm{hPa}$ deg $\mathrm{ms}^{-1}$

$\mathrm{ms}^{-1}$

$\mathrm{ms}^{-1}$

${ }^{\circ} \mathrm{C}$

${ }^{\circ} \mathrm{C}$

$\%$

$\mathrm{g} \mathrm{m}^{-3}$

${ }^{\circ} \mathrm{C}$

$\mathrm{Wm}^{-2}$

ppbv

ppbv

ppbv

$\mathrm{s}^{-1}$

deg

$\mathrm{m}$

$\mathrm{hPa}$ deg $\mathrm{ms}^{-1}$

$\mathrm{ms}^{-1}$

$\mathrm{ms}^{-1}$

${ }^{\circ} \mathrm{C}$

${ }^{\circ} \mathrm{C}$

$\%$

ppbv

ppbv

GPS=Global Positioning System. INS=Inertial Navigation System. 
completed and the Dornier-Aztec directly flew back to A1 after the ascent. Only the ascending part will be used in the comparison.

- Wind legs: four horizontal and stabilised legs are flown according to the four directions relative to the wind direction (the wind comes from the west/north-west). So the P3 leg is along wind, and flown from A4 to A3; P4 is parallel but upwind and flown from A6 to A5, both at $800 \mathrm{~m}$. P5 and P6 are cross-wind, with P5 from A4 to A7 to the south, at $800 \mathrm{~m}$ and $\mathrm{P} 6$ backwards at $500 \mathrm{~m}$. Each aircraft flew at its own velocity relative to the air.

- Turbulent legs: these horizontal and stabilised legs (P8 and P9, from A8 to A9 and back, respectively, at 470 and $150 \mathrm{~m}$ ) are designed to compare the turbulent moments and the fluxes. They are shorter than the others because they require homogeneous surface conditions. The Crau plain was chosen to meet this requirement. This section is not flown wing to wing but the time delay between two airplanes is no more than $60 \mathrm{~s}$.

\subsection{Instrumentation}

Details of the instrumentation used on each aircraft are listed in Table 3. They can also be found in the works of Hankers (1989), Corsmeier et al. (2001), Druilhet and Durand (1997), and Lambert and Durand (1998). Only aircraft ARAT, Dornier, and Merlin were equipped for turbulence measurements. To do so, the ARAT and Merlin used a nose radome with five pressure ports (one in the center for total pressure sampling and four others along two perpendicular axes for differential pressure sampling) to calculate the attack and sideslip angles as well as the wind vector relative to the aircraft. Temperature and humidity sensors were located close to this radome to avoid phase-shift between dynamics and thermodynamics. All measurements are computed at 16 and 25 $\mathrm{Hz}$, respectively, for the ARAT and Merlin. On the Dornier, air speed, angles of attack and sideslip, as well as the static pressure are measured at the tip of a 4-m nose boom with the help of a Rosemount five-holes probe and pressure transducers. Other air sensors are located on the fuselage in front of the windshield. The computing frequency is $25 \mathrm{~Hz}$.

\subsubsection{Temperature sensors}

Temperature is measured by platinum wires, $30 \mu \mathrm{m}$ in diameter, sheltered in a housing, and shaped to ensure airflow velocity with respect to the wire, be near zero. Correction for compression heating was done, to obtain the static temperature value (Vörsmann, 1985; Lefebvre et al., 1999). The frequency range of this kind of sensor (typically up to $10 \mathrm{~Hz}$ ) depends on the wire diameter and on the housing. For faster measurements, open-wire sensors are used on the Dornier and Merlin. Their performances are not studied in this paper.

There are four temperature sensors on board the Merlin and the ARAT. These sensors have been conceived in the same way (platinum wire resistance) but three of them are adapted to peculiar situations: two of them have a deicing system, the third one is a 'reverse-flow' sensor. The classical sensor, which is the fastest, is used in priority. 


\subsubsection{Humidity sensors}

Different classical methods are used to measure humidity. They are well described by Ström et al. (1994).

- Dew-point sensor (thermal principle: temperature control of a cooling mirror): this sensor provides an absolute measurement of the mixing ratio, without any time drift, but its time response which is around $1 \mathrm{pt} / \mathrm{s}$, does not allow turbulence measurements. This sensor is used on three of the four airplanes (and is even duplicated on the ARAT and Merlin as a spare): however, previous experiments showed that even for two similar models, results may vary according to the sensor location on the aircraft or specific recover of the sensor after rapid change of humidity.

- Capacitive humidity sensor (electrical principle): the time response of this sensor is better than that of the dew point sensor and is more suited to detecting transitions. However, it is not used as a primary sensor since it slightly drifts with time.

- LYMAN $\alpha$ (optical principle: absorption): it is used for fast measurements (up to 100 $\mathrm{Hz}$ ). This sensor does not provide an absolute measurement and furthermore drifts with time. So it is calibrated against the dew-point low measurements. For the Merlin and ARAT, this calibration is made using a regression after adjusting the frequencies in the low frequency range. Two different models are used on the ARAT: the ERC is only used for spare since its frequency range is not as high as the AIR one. For the Dornier, the data from the Lyman $\alpha$ are merged to those of a Humicap capacitive sensor by complimentary filtering of the fast and low data (Corsmeier et al., 2001). The obtained signal is averaged again at $1 \mathrm{pt} / \mathrm{s}$ for the mean parameters study (Section 3 ).

\subsubsection{Position (low frequency measurements)}

It is determined from Global Positioning System (GPS) measurements for latitude and longitude. Most aircraft (except the Aztec) are also equipped with an Inertial Navigation System (INS) which provides information about position. The INS systems are known to drift away with time (the main Schuler oscillation component, which is $84.4 \mathrm{~min}$, is one of the various drifts). The nominal positioning deviation is 1 nautic mile/h (i.e. $1.8 \mathrm{~km} /$ hour). A comparison of the GPS/INS position made on the ARAT and Merlin showed that the effective error on these flights was always lower than $1 \mathrm{~km}(400 \mathrm{~m} / \mathrm{h})$ in latitude and 740 $\mathrm{m}(300 \mathrm{~m} / \mathrm{h})$ in longitude, which is accurate enough for the ESCOMPTE purposes. So the INS horizontal position measurements have been used as a spare in the data base (after drift correction) when the GPS signals failed. This occurred several times during the experiment.

The altitude $Z$ has been computed using static pressure measurements made on the radome or on the fuselage according to the aircraft, and the information on the pressure at sea level obtained from the control tower. $Z$ is then calculated with the Laplace formula.

On the opposite, the Dornier which is also devoted to remote-sensing measurements such as cartography, requires more precise navigation. In this case, the Dornier uses the online differential GPS, either with foreign correction signals (Radio Technical Committee for Maritime Services) or with self-generated correction data from the ground via an own data link (Corsmeier et al., 2001). This provides an accuracy of much better than 1-m position error. This possibility was used during ESCOMPTE for a side-project in cartography. 
The height of the overflown relief is deduced from the difference between $Z$ and the altitude to the ground, measured by the ground altimeter. It is to be noted that on the Piper Aztec and the Dornier, this sensor is limited respectively to 1600 and $700 \mathrm{~m}$.

\subsubsection{Wind}

The most complex measurements concern the three wind components. The wind vector is computed as the sum of both vectors: ground speed, velocity of the aircraft in the Earth coordinate system and true-airspeed, velocity of the aircraft relative to the air. The result is, in general, an order of magnitude smaller than each of these two terms and thus requires careful measurements and calibrations. The three components of the ground speed vector are measured by the INS, except on the Piper Aztec whose measurement system will be described further down. The three components of the true air speed vector are computed from the module $V$ and the two angles of attack $(\alpha)$ and sideslip $(\beta) . V$ is computed from the dynamic pressure $\Delta P$ (difference between the total and static pressures). $\alpha$ and $\beta$ are calculated from the differential pressure measured between the radome or nose-boom holes. Whereas the whole set of equations is used for the Dornier and Merlin, the three wind components $\left(u_{\mathrm{N}}, u_{\mathrm{E}}\right.$ and $w$ in the north, east and vertical direction, respectively) are computed for the ARAT with the Lenschow (1986) simplified formulae where the angles except the true heading are considered as small:

$$
\begin{aligned}
& u_{\mathrm{N}}=U_{\mathrm{N}}-T A S \cos (\Psi+\beta)-l \dot{\Psi} \sin \Psi \\
& u_{\mathrm{E}}=U_{\mathrm{E}}-T A S \sin (\Psi+\beta)+l \dot{\Psi} \cos \Psi \\
& w=W+T A S(\alpha-\Theta)+l \dot{\Theta}
\end{aligned}
$$

where $\Psi$ and $\Theta$ are the true heading and the pitch angle of the aircraft (both measured by the INS). $U_{\mathrm{N}}, U_{\mathrm{E}}$, and $W$ are the three components of the groundspeed vector in the (north, east and vertical) coordinate system. $l$ is the distance between the INS and the anemometric measurements. It is 11 and $6 \mathrm{~m}$ for the ARAT and Dornier respectively, for which the INS is located at the gravity center of the aircraft, and it is negligible for the Merlin for which the INS is situated in the nose of the aircraft. When including all uncertainties linked to the sensors, calibrations and calculations, Lefebvre et al. (1999) indicate an overall uncertainty of $1.2 \mathrm{~ms}^{-1}$ on the Merlin windspeed, whatever the wind velocity, of $30^{\circ}$ on the wind direction for weak winds and $7^{\circ}$ for moderate ones.

A well-known source of error on wind measurements is linked to the drift of the INS. Quante et al. (1996) propose to correct this drift, using the information from GPS. They show that the absolute accuracy of mean horizontal wind components can be improved from 1.5-2 to $0.3-1 \mathrm{~ms}^{-1}$. We did not try to apply this correction neither on the ARAT (poor quality GPS information) nor on the Merlin but we will comment this possibility in next section.

On the opposite, the Dornier combines the online differential GPS data to the Lasernav INS data to improve the quality of wind computation and avoid drifting (Lipp et al., 1995). In this way, an accuracy of about $0.5 \mathrm{~ms}^{-1}$ can be reached for the horizontal wind components and $0.1 \mathrm{~ms}^{-1}$ for the vertical (Brümmer, 1993; Corsmeier et al., 2001). The detail of the calculation is presented by Vörsmann (1985) and Hankers (1989). 
On the Piper Aztec, wind measurements are performed using the Doppler radar information (Piguet and Méquignon, 2000). The Doppler velocity is deduced from the measurement of the three components from three beams with azimuths disposed $120^{\circ}$ apart with a zenith angle of $20^{\circ}$ relative to the aircraft vertical. The Doppler signal is first smoothed using a 8-s running mean. The calculation is made in the aircraft coordinate system and converted afterwards in the Earth coordinate system. The horizontal wind components in the aircraft system are:

$$
\begin{aligned}
& U_{\mathrm{a}}=V_{x}-T A S \cos (\beta) \\
& V_{\mathrm{a}}=V_{y}-T A S \sin (\beta)
\end{aligned}
$$

where $V_{x}$ and $V_{y}$ are the components of the groundspeed in the aircraft coordinate system. $U_{\mathrm{a}}$ and $V_{\mathrm{a}}$ are then calculated in the Earth coordinate system, using the true heading information. So no correction has been done for pitch and roll since they are not measured: the AZTEC wind is therefore only valid for horizontal flight sections.

It has to be noted that the Doppler wind may be disturbed over the sea due to surface streams or swell. In this case, the GPS wind can be used as a spare. For routine measurements, the Doppler wind is preferred to the GPS wind to minimize the error linked to the true heading measurement.

\subsubsection{Radiation measurements}

On the ARAT, Dornier and Merlin radiation measurements involve the four components of the net radiation, i.e. the downward and upward radiation in short and long wavelengths. The measurement is made at low frequency with a $2 \pi$ sr solid angle. The shortwave measurements are corrected for aircraft attitude but nevertherless, the data are reliable only on straight and level runs. The longwave radiations are corrected for the cup temperatures. We made the comparison along the lowest level leg only (P6): it provided the largest range of surface radiations. A more accurate measurement of the surface temperature is also provided by downward facing radiometers that measure the long-wave spectral window band between 8 and $14 \mu \mathrm{m}$, with an aperture angle of $2.25^{\circ}$ on the Dornier and $3^{\circ}$ on the ARAT and Merlin. When flying at $500 \mathrm{~m}$, this corresponds approximatively to a 40-m diameter of spot seen on the earth's surface. The flux measurement provided by these sensors is directly converted into surface temperature $\left({ }^{\circ} \mathrm{C}\right)$ without correction of surface emissivity nor atmospheric attenuation.

The Dornier also performed during ESCOMPTE remote-sensed measurements of the surface, using a spectral linescanner measuring at three wavelengths in the visible and near infrared band as well as a digital camera for measurements in the visible region. There is no measurement of this kind on the other airplanes.

Finally, the Merlin and the ARAT are equipped with two radiation sensors (for both upward and downward measurements) able to measure $J_{\mathrm{NO}_{2}}$, the photolysis dissociation coefficient of $\mathrm{NO}_{2}$ into NO. These sensors are radiometers commercialized by Meteorologie Consult (Germany) that use band-pass filters designed to simulate the absorption cross section-quantum yield product of the molecule of $\mathrm{NO}_{2}$. 
These sensors need to be calibrated against chemical actinometers. This was done for the ARAT sensor just before the campaign with a $J_{\mathrm{NO}_{2}}$ master calibrated by chemical actinometry.

After the experiment, an intercalibration of the radiation sensors has been performed at the CEMAGREF (Agricultural and Environmental Engineering Research Institut) in France. The calibration coefficients are the following:

$$
\begin{aligned}
& \text { ARAT } \quad J_{\mathrm{NO}_{2}}^{H}=\left(6.58406 J_{\mathrm{NO}_{2}}^{h}-0.09638\right) 10^{-3} \\
& J_{\mathrm{NO}_{2}}^{B}=\left(6.926 J_{\mathrm{NO}_{2}}^{b}-0.244\right) 10^{-3}
\end{aligned}
$$

$H$ and $h$ refer to downward radiation, with $h$ for the raw data in $\mathrm{V}$ and $\mathrm{H}$ for the calibrated one in $\mathrm{s}^{-1} . B$ and $b$ are for upward radiation.

$$
\text { MERLIN } \quad J_{\mathrm{NO}_{2}}^{\mathrm{H}}=0.0042 J_{\mathrm{NO}_{2}}^{h}+0.0004
$$

$h$ and $H$ are in $\mathrm{mV} . J_{\mathrm{NO}_{2}}^{B}$ from Merlin has not been calibrated in time, and due to the irregular time drift of the sensor, it has not been done afterwards either. So, only raw data are available. So we will use the ARAT-Merlin comparison flight to provide physical values of $J_{\mathrm{NO}_{2}}^{B}$ on the Merlin.

\subsubsection{Chemical compounds}

2.2.6.1. Ozone. Each of the four airplanes performed low frequency ozone measurements with classical sensors using UV absorption. The ozone mixing ratio depends on the pressure and temperature in the measurement chamber. These two parameters are measured and the correction is made directly inside the sensor. The Dornier sensor is calibrated at the Institut für Meteorologie und Klimaforschung before and after every experiment (Wieser, 2004). The ARAT, Aztec and Merlin sensors were compared at the ground during a quality control experiment at the Avignon airport, just before ESCOMPTE, using an ozone generator LNI Sonimix 3001, with varying pressure levels. Furthermore, ozone in-flight data were compared during this period to lidars, radiosounding and the ULM from IFU. The deduced calibration coefficients from both ground and airborne comparisons are the following :

The subscript 'raw' indicates the measurement value (in $\mathrm{mV}$ for Merlin and Aztec, directly in ppbv for ARAT, as provided by the sensor) and the left parameter is the calibrated parameter (ppbv). 
The time responses/detection limit/constructor accuracy/measured overall accuracy (calibration and drift) of the various sensors are the following:

Environment $\mathrm{O}_{3}-41 \mathrm{M}$ Aztec: $7 \mathrm{~s} / 0.5 \mathrm{ppbv} / 1.4 \mathrm{ppbv} /-$

Environment $\mathrm{O}_{3}-41 \mathrm{M}$ Dornier: $2 \mathrm{~s} / 0.5 \mathrm{ppbv} / 1.4 \mathrm{ppbv} / 20.3 \%$ for $63 \mathrm{ppbv}$ (Wieser, 2004) Thermo Electron 49PS and 49C ARAT and Merlin: 4s/1ppbv/-/-

The Dornier and Merlin aircraft also operated fast ozone sensors both belonging to the IMK. The sensors were used from July 2 to 13 only on the Merlin and during the whole period on the Dornier. The measurement is based on chemiluminescence (Güsten et al., 1992). The emitted beam is detected by a photomultiplier sensitive to blue wavelengths (400-500 nm). On the Merlin, a ventilator provides a constant flow in the detection chamber while on the Dornier, the stream is controlled by the aircraft speed. For a 1001 $\min ^{-1}$ flow, Güsten et al. (1992) indicate a time response lower than $0.1 \mathrm{~s}$ and a detection limit of $30 \mathrm{ppt}$. This sensor provides a signal proportional to ozone fluctuations so it is calibrated, for the Merlin data, against the low measurements sensor (as is done for fast humidity measurements). On the Dornier, the high-frequency fluctuation measurements are merged with the absolute ozone measurements with low resolution by complementary filtering. The resulting accuracy for the coupled system is $3.6 \%$ for $63 \mathrm{ppbv}$ (Wieser, 2004).

Unfortunatly, the Dornier and Merlin that were the only airplanes to provide fast measurements of ozone were not chosen to fly together (due to their large difference in velocity) and the two sensors have not been compared.

2.2.6.2. Carbon monoxide. On the Dornier, an AeroLaser analyser working with the vacuum UV resonance-fluorescence (RF) method described by Gerbig et al. (1999) is used for the measurement of carbon monoxide. The instrument consists of a resonance lamp excited by a RF discharge, an optical filter for selection of the appropriate wavelength interval around $150 \mathrm{~nm}$, which images the lamp into the RF chamber, where the fluorescence is viewed by means of a photomutiplier tube. The precision is $\pm 1.5 \mathrm{ppbv}$ at an atmospheric mixing ratio of $100 \mathrm{ppb}$, and the detection limit is $3 \mathrm{ppbv}$ for an integration time of $1 \mathrm{~s}$. Every $4 \mathrm{~min}$, the signal is reset to zero. On the ARAT and Merlin, the CO analysers are commercial models from Thermo Electron modified by the Laboratoire d'Aérologie for the aircraft involved in the MOZAIC program (Nedelec et al., 2003). They work according to the principle of infra-red absorption by the $4.67-\mu \mathrm{m}$ fundamental vibration-rotation band of CO. Radiation from an infrared source is chopped and passes through a gas filter which alternates between $\mathrm{CO}$ and $\mathrm{N}_{2}$ due to the rotation of the filter wheel. The radiation then passes through a narrow band pass filter and a multiple optical path sample cell where absorption by the sample gas occurs. The IR radiation excites the sample cell and falls on a PbSe solid state IR detector. Other gases do not cause modulation of the detector signal since they absorb the reference and measure beams equally. Thus, the Gas Filter Correlation System responds specifically to CO. The specification of the commercial instrument is $10 \mathrm{ppbv} \mathrm{CO}$ for a 300 -s integration time.

Several major changes have been made by the Laboratoire d'Aérologie (Nedelec et al., 2003 ) in order to improve its characteristics: periodic accurate zero measurements, new IR 
detector with better cooling and temperature regulation, pressure increase and regulation in the absorption cell, increased flow rate to $41 \mathrm{~min}^{-1}$, water vapor trap, ozone filter. The specifications achieved are the following for a 30 -s integration time: precision \pm 5 ppbv $\mathrm{CO}$, detection limit $10 \mathrm{ppbv} \mathrm{CO}$. The signal is set to zero every $18 \mathrm{~min}$. The time drift between two successive zero values is corrected. It has to be noted, however, that the Merlin is not equipped for pressure regulation and water vapor trap. The corrections are made using the pressure measurement performed inside the chamber and the mean water content value measured with the dew point hygrometer.

2.2.6.3. Trace gases. $\mathrm{NO}_{2}, \mathrm{NO}_{x}, \mathrm{PAN}, \mathrm{NO}_{y}$ : The four aircraft measured these gases using an analyser developed at the LISA Institut (MONA) or by MetAir (Switzerland). The $\mathrm{NO}_{x} \mathrm{TO}_{y}$ sensor commercialized by MetAir is on the basis of the chemiluminescence reaction of $\mathrm{NO}_{2}$ with Luminol. It is a four channel analyzer for $\mathrm{NO}_{2}, \mathrm{NO}_{x}, \mathrm{NO}_{x}+\mathrm{PAN}$ and $\mathrm{NO}_{y} . \mathrm{NO}_{2}$ is measured directly, $\mathrm{NO}_{x}$ by a $\mathrm{CrO}_{3}$ converter. $\mathrm{NO}$ is calculated as difference of $\mathrm{NO}_{x}-\mathrm{NO}_{2}$, corrected for conversion efficiency $\mathrm{NO}$ to $\mathrm{NO}_{2}$ of $\mathrm{CrO}_{3}$ converter (around $70 \%)$. PAN is measured by thermal conversion as difference of $\mathrm{NO}_{x}\left(\mathrm{NO}_{2}+\mathrm{NO}\right)$ and $\mathrm{NO}_{x}+$ PAN. Efficiency is assumed as $100 \%$.

The $\mathrm{NO}_{x} \mathrm{TO}_{y}$ on board the Aztec and Merlin had just been brought for the ESCOMPTE experiment and they revealed difficult to handle. In fact the IMK team had themselves performed important modifications on their own $\mathrm{NO}_{x} \mathrm{TO}_{y}$ sensor (Wieser, 2004): they use four mass flow controllers and a vacuum pump to regulate flow to $100 \mathrm{ml} \mathrm{min}^{-1}$ for each channel. Luminol in the instrument is stocked in a plastic bag without any contact with air. The peristaltic pump of the commercial model has been kept. The whole compartment containing measurement cells and Luminol stock is regulated at $25{ }^{\circ} \mathrm{C}$. Humidified air is used for calibration since there is a strong dependency of conversion efficiency of $\mathrm{CrO}_{3}$ (Hutchinson et al., 1999). Due to the different tube lengths and different converters used for the four channels, corrections of delay and inertia have to be done: for instance, to calculate the $\mathrm{NO}$ concentration as described above, the $\mathrm{NO}_{2}$ and $\mathrm{NO}_{x}$ channel data have to be corrected for delay and inertia and filtered to the maximum frequency of the slower channel $\left(\mathrm{NO}_{x}: \sim 5 \mathrm{~Hz}\right)$. If this is not correctly done, negative $\mathrm{NO}$ concentrations may arise. The resulting characteristics are the following (detection limit/overall accuracy including calibration gas, calibrator, zero drift and span drift for 2 or/12 ppb):

$\mathrm{NO}_{2}: 18 \mathrm{pptv} / 8.8 \% / 8.7 \%$

$\mathrm{NO}_{x}: 20 \mathrm{pptv} / 11.6 \% / 10.0 \%$

There are until now problems with $\mathrm{NO}_{y}$ measurements.

The MONA analyzer that was installed onboard ARAT was specially design by LISA for nitrogen compounds ( $\left.\mathrm{NO}, \mathrm{NO}_{2}, \mathrm{NO}_{y}, \mathrm{PAN}\right)$ airborne measurement. $\mathrm{NO}$ was measured with high sensitivity chemiluminescent analyzers (Eco Physics CLD 780 TR) especially designed for aircraft. In this apparatus, $\mathrm{NO}_{2}$ is converted to $\mathrm{NO}$ by photolysis and subsequently measured by chemiluminescence. The resolution time is $30 \mathrm{~s}$. A complete description of the instrumentation can be seen in the work of Marion et al. (2001). All the instruments were compared at the ground at the beginning of the campaign. The NO and $\mathrm{NO}_{2}$ analyzers were calibrated before and after each flight. During this campaign, we ran 
the analyzers with an integration time of $12 \mathrm{~s}$, allowing a sample time step of $30 \mathrm{~s}$. For these conditions, the detection limit for each NO analyzer is 50 pptv and the accuracy of the analyzer is $0.5 \%$. These values are calculated using a statistical treatment following a French norm (AFNOR NF X20-300) (Marion et al., 2001).

2.2.6.4. Carbon dioxide. The Dornier was the only aircraft to provide measurements of carbon dioxide using a LICOR instrument with infra-red absorption. The sampling reached $5 \mathrm{~Hz}$.

\section{Comparison of the $1 \mathrm{pt} / \mathrm{s}$ measurements}

\subsection{Comparison during the vertical exploration}

Before doing this study and to limit it to only one sensor for each parameter measured, the redundant sensors were first examined. It is the case for the temperature and the water vapor content on the Merlin and on the ARAT. In addition, the ozone measurements of the ascending part of the vertical exploration were compared with those of the descending part for each aircraft, to make sure that the aircraft attitude or the transition from wet to dry or vice-versa did not affect the measurement. The results of the comparison are reported here, but the curves are not shown for temperature and humidity since the differences are very weak.

Slight differences appeared in the measurements of the four temperature sensors. They were quantified by calculating the two by two sensors correlations during the ascending phase. The differences, however, always remained lower than $0.3 \mathrm{~K}$, so no correction was proposed at this stage. This value is less than the overall theoretical accuracy $(0.5 \mathrm{~K})$ estimated by Lenschow (1986).

In the same way, the two dew-point sensors on the ARAT and Merlin as well as the dew-point and capacitive sensors on the Aztec were compared. The comparison is relative to the mixing ratio in $\mathrm{g} \mathrm{kg}^{-1}$. Surprisingly, the comparison was better for the two ARAT sensors during flight 51 than during flight 50 . This showed that a possible correction may be useless, since the difference was not systematic. On the Merlin, the difference never exceeded $0.2 \mathrm{~g} \mathrm{~kg}^{-1}$ (less than 4\%) which is a little higher than the theoretical overall accuracy proposed by Lefebvre et al. (1999): $1.2 \%$ to $1.5 \%$. The comparison on the Aztec sensors showed that the dew-point hygrometer measurements and those of the capacitive sensor are interchangeable, even if the capacitive sensor slightly underestimates low humidity. The capacitive sensor is known to drift with time so it must be used with care in case of dew-point sensor breakdown.

All people measuring ozone may have checked that measurements performed in climbing sounding phase do not coincide with those made in descending phase, since during the sounding phase, the aircraft very often samples ozone concentration transitions which are too quick for the response time of the sensors. This point was checked on the data of these flights. It was first necessary to make sure that the climbing and sinking rates of the aircraft were comparable and reasonable: they remained in the range [375-465] $\mathrm{ft}$ $\min ^{-1}$ which is lower than $500 \mathrm{ft} \mathrm{min}^{-1}$, the standard rate for vertical explorations. One 
example is presented in Fig. 2 for the Merlin-ARAT flight. This figure shows that the climbing and sinking comparison is good. The only difference occurs inside the mixed layer whose ozone concentration increased during the 40-min lapse time between the ascent and descent. The results are similar for the other aircraft and flights.

So we will highlight the following point: these results are good because the climbing and descending rates remained lower than $500 \mathrm{ft} \mathrm{min}^{-1}$. This was not the case of most descents during ESCOMPTE that were flown quickly to save time. So the data base user is invited to check this speed before using these data. Anyway all vertical explorations included either an ascending or descending sequence performed in good conditions.

The thermodynamical and chemical parameters are compared during the ascending vertical exploration phase, since the aircraft pairs fly wing to wing and thus analyze the same air parcels. The vertical exploration goes from 300 to $3000 \mathrm{~m}$, which enables a wide variation range of the parameters. It includes a bending portion but a checking was performed to make sure that it does not alter measurements. The horizontal overflown distance is around $80 \mathrm{~km}$. The comparison is made by plotting the parameter of one aircraft vs. the same parameter for the other aircraft; a point by point intercomparison is thus sought. The equation of the regression line is indicated on each curve. The results are presented in Fig. 3 for pressure (a) temperature (b), water vapor content (c) and ozone concentration (d).

\subsubsection{Static pressure}

The very good correlation on pressure for the Dornier-Aztec pair (diagram Aa) shows that the two aircraft flew strictly at the same level. The Dornier-ARAT comparison (diagram Ba) shows, when enlarged, that the ARAT flew slightly higher than the Dornier, with a maximum difference of $6 \mathrm{hPa}$, which corresponds to about $60 \mathrm{~m}$. The Merlin and the ARAT did not maintain the wing-to-wing fly at the end of the sounding (diagram $\mathrm{Ca}$ ), where the difference may reach $25 \mathrm{hPa}(250 \mathrm{~m})$, as confirmed by the GPS measurements.

\subsubsection{Temperature}

Diagrams b in Fig. 3 displays regression lines parallel to the 1:1 slope with slight discrepancies between the airplanes, which become more marked when the temperature increases: for a temperature of $18{ }^{\circ} \mathrm{C}$, the differences between Dornier and Aztec (diagram $\mathrm{Ab}$ ), Dornier and ARAT (diagram $\mathrm{Bb}$ ) and Merlin and ARAT (diagram $\mathrm{Cb}$ ) are $0.8,-0.85$ and $-0.65 \mathrm{~K}$, respectively. The ARAT thus seems to slightly overestimate static air temperature. The measurements used in this intercomparison were those of the classical sensor which revealed to be slightly higher than the deiced and reverse-flow sensors in the case of the ARAT. It will be thus necessary to contemplate the possibility of correcting the ARAT classical Rosemount by reducing it to get closer to the deiced sensor (intermediary value). This correction has been preferred to a correction on the primary parameters (such as recovery factor, true air speed, static pressure) after looking at the comparison between the measured (not corrected) temperatures. They had shown the same tendencies as those underlined above. It has however to be noted that the accuracy obtained for temperature is sufficient for the ESCOMPTE measurements. 

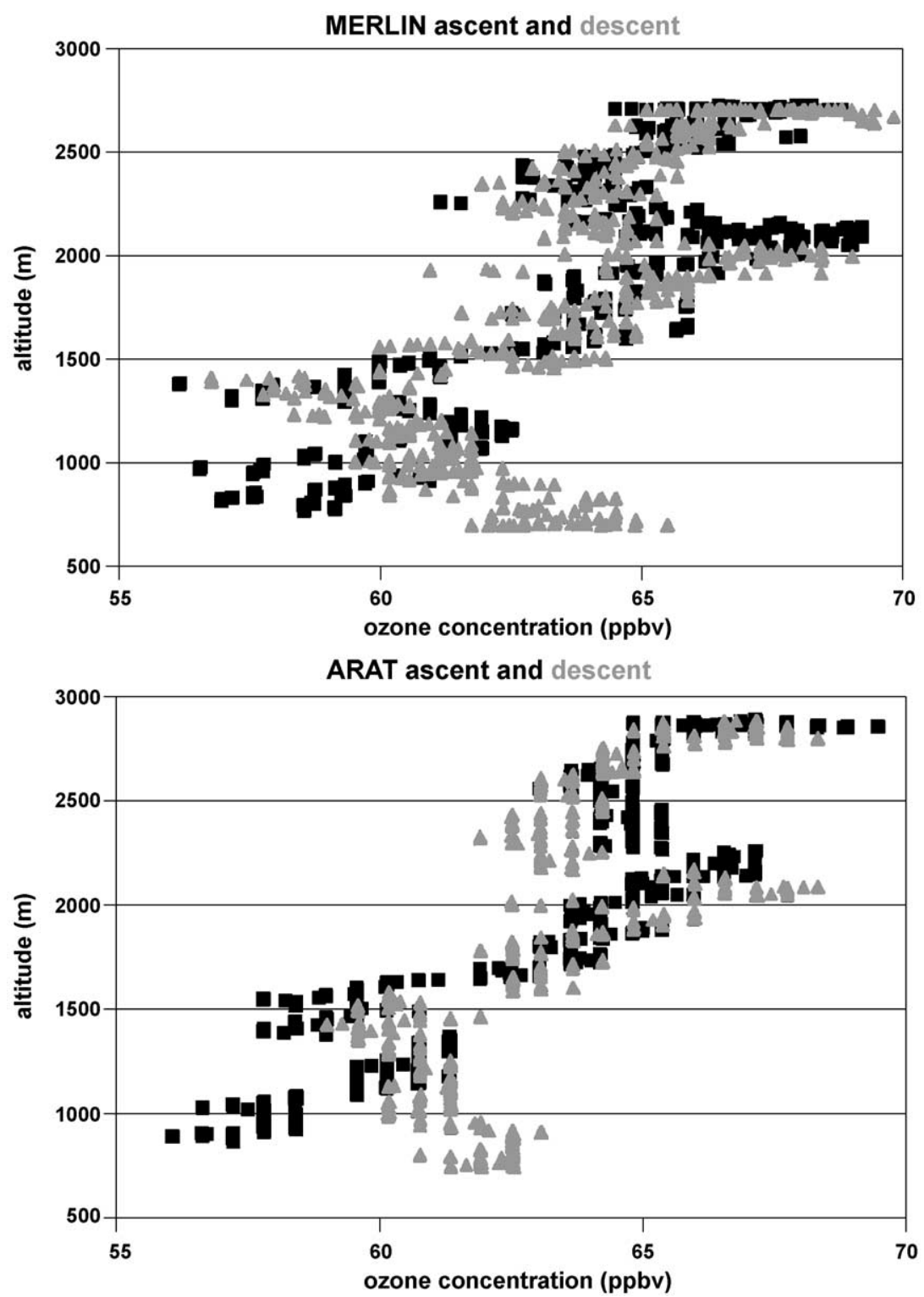

Fig. 2. Comparison of the ozone concentrations in the ascending (black squares) and descending (grey triangles) parts of the vertical exploration from Merlin (top) (Thermo Electron 49C) and ARAT (bottom) (Thermo Electron 49PS). Each point is $10 \mathrm{~s}$ averaged.

So the final correction applied to the ARAT classical Rosemount temperature was (all temperatures are in ${ }^{\circ} \mathrm{C}$ ):

$$
\operatorname{ROS}_{\mathrm{ARAT}}(\text { corrected })=0.9933 \operatorname{ROS}_{\mathrm{ARAT}}-0.205
$$



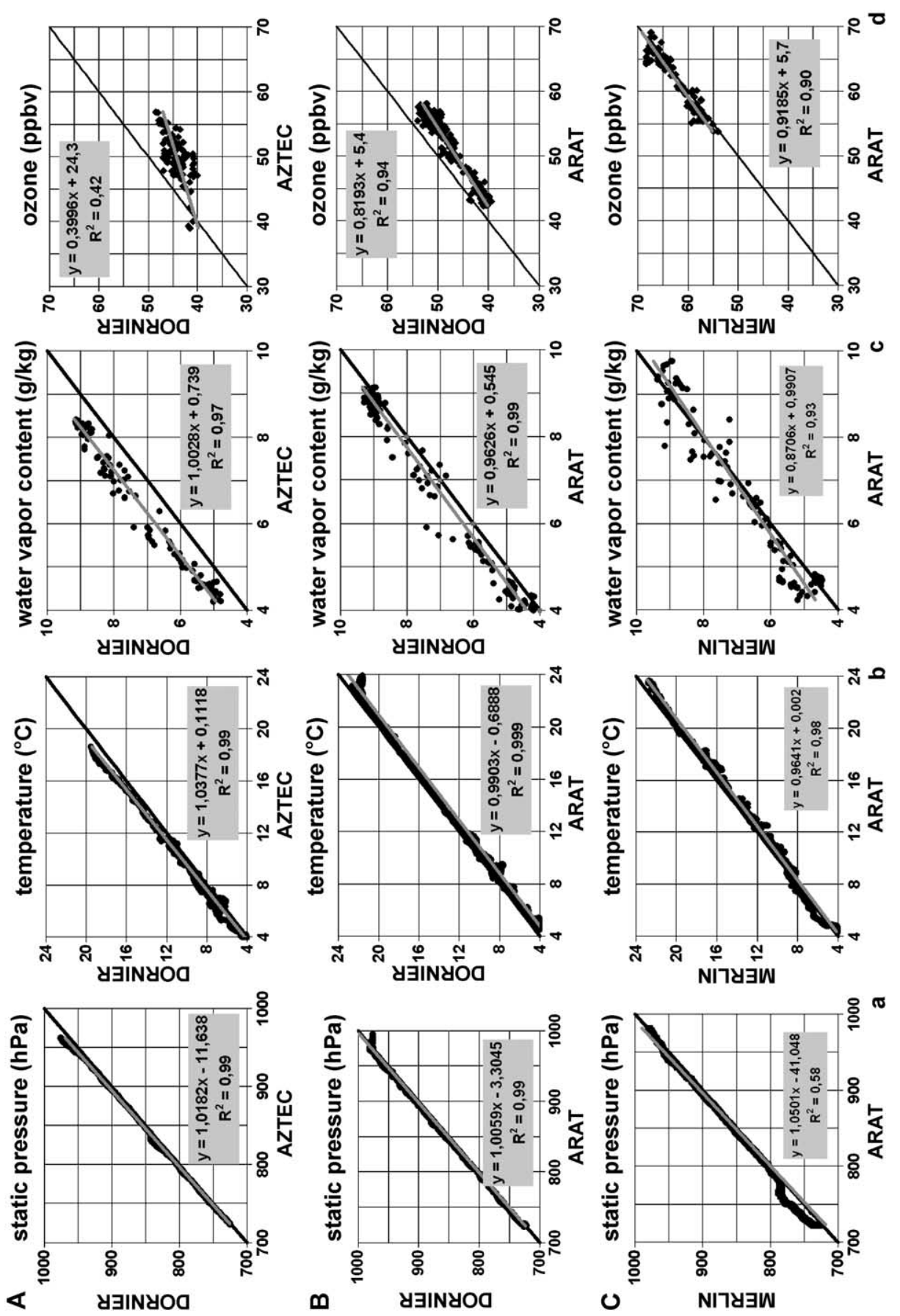
This led to the following two improved regressions (not shown) for the Dornier and Merlin:

$$
\begin{aligned}
& \text { DORNIER } \left.=1.015 \operatorname{ROS}_{\mathrm{ARAT}}(\text { corrected })-0.45 \text { (upper difference }: 0.38{ }^{\circ} \mathrm{C} \text { at } 5{ }^{\circ} \mathrm{C}\right) \\
& M E R L I N=0.9597 \operatorname{ROS}_{\mathrm{ARAT}}(\text { corrected })+0.38\left(\text { upper difference: } 0.42{ }^{\circ} \mathrm{C} \text { at } 20{ }^{\circ} \mathrm{C}\right) .
\end{aligned}
$$

The differences have been visibly reduced.

A correction was also brought to the Aztec temperature to increase it to the level of the Dornier measurement. The new temperature is written as follows:

$$
\text { AZTEC }(\text { corrected })=1.0359 \text { AZTEC }+0.113
$$

Finally, we will keep in mind a temperature difference that will be systematically lower than $0.4 \mathrm{~K}$ which is in the range indicated for other experiments (Lambert and Durand, 1998: 0.15 to 0.5 K; Quante et al., 1996: 0.5 K). However, MacPherson et al. (1992), who found an accuracy of $0.2 \mathrm{~K}$, declare it not accurate enough for budget calculations.

\subsubsection{Water vapor mixing ratio}

The cooled mirror operates with a control cycle of a few seconds. The measurements were thus averaged to $1 \mathrm{pt} / 10 \mathrm{~s}$ to decrease the regression scattering. The Merlin-ARAT comparison is good (diagram Cc): the regression line follows the 1:1 slope but the points are more scattered than for the other comparisons (diagrams Ac and $\mathrm{Bc}$ ). This point is not explained. The mixing ratio measured by the Dornier is higher than that measured by the ARAT (diagram $\mathrm{Bc}$ ). The regression line indicates that the difference depends on the value; it seems to be higher for weak values but it must be noted that high mixing ratio points, which are in the boundary layer, are more numerous and thus influence the slope. For the Aztec and Dornier (diagram Ac), the regression is biased, with the Dornier always $0.8 \mathrm{~g} \mathrm{~kg}^{-1}$ higher than the Aztec. We conclude that the Dornier overestimates humidity since its measurements are higher than the AZTEC's, the ARAT's and consequently the Merlin's which are the same as the ARAT's. The following correction in the mixing ratio $\left(\mathrm{g} \mathrm{kg}^{-1}\right)$ given by the Dornier is thus proposed, taking into account the two regression lines obtained with the Aztec and the ARAT:

$$
r_{\text {DOR }}(\text { corrected })=1.047 r_{\text {DOR }}-0.904
$$

The new regression lines are not shown here. They result in a discrepancy always lower than $0.3 \mathrm{~g} \mathrm{~kg}^{-1}$ which remains in the theoretical sensitivity range of the cold mirror sensors $\left(0.5 \mathrm{~K}\right.$, which is about $0.2 \mathrm{~g} \mathrm{~kg}^{-1}$ in the boundary layer). This result is slightly less good than the SEMAPHORE result (Lambert and Durand, 1998) $\left(0.14 \mathrm{~g} \mathrm{~kg}^{-1}\right.$ ) but far

Fig. 3. Comparisons of static pressure (a), static temperature (b), water vapor content (c) and ozone concentration (d) during the ascents of the three aircraft pairs: Dornier-Aztec (A), Dornier-ARAT (B) and Merlin-ARAT (C). Thin black line $=1: 1$ slope line. Thick grey line=regression line. Each point is $1 \mathrm{~s}$ average for pressure and temperature, $10 \mathrm{~s}$ for ozone and humidity. 
better than the FIFE one (MacPherson et al., 1992) $\left(2 \mathrm{~g} \mathrm{~kg}^{-1}\right)$. During pre-EUCREX, Ström et al. (1994) performed a very tight comparison of humidity sensors working in the upper troposphere, where humidity is very low. With the exception of the capacitance and resistance instruments, their sensors, among which several were fast sensors, reached agreement in mixing ratio to within $\pm 5 \%$ for values down to about $0.1 \mathrm{~g} \mathrm{~kg}^{-1}$. The ESCOMPTE results are far from this accuracy but remain in an honorable range of accuracy for boundary-layer measurements.

However, we warn the data base user that the dew point sensors are not always reliable and that during some flight sections, the spare sensor (or sometimes the fast sensor) has been used instead of the main sensor.

\subsubsection{Ozone concentration}

The results are shown in Fig. 3 (diagrams d), where the points have been averaged at 1 $\mathrm{pt} / 10 \mathrm{~s}$ to avoid discrepancies linked to the time response of the sensors. The MerlinARAT comparison (diagram $\mathrm{Cd}$ ) gives good results. Although the Merlin provides slightly higher concentrations than the ARAT (4 ppbv higher in the worst case), the regression line is unbiased. The Dornier-ARAT (diagram Bd) displays a roughly constant difference of 5 ppbv. Anyway, we did not apply any correction, considering that 5 ppbv is accurate enough for the ESCOMPTE purpose. The comparison between the Dornier and Aztec (diagram Ad) highlights a problem of the Aztec measurement during the sounding phase since the difference is not such large along the horizontal runs (where it remains some ppbv higher on the Aztec than on the Dornier). The pressure and temperature measurements inside the measurement chamber may be erroneous. So the ozone Aztec measurements will have to be taken with caution during vertical explorations (difference of $10 \mathrm{ppbv}$ here that may increase for higher ozone concentrations).

\subsection{Other chemical measurement comparisons}

Carbon monoxide as well as $\mathrm{NO}_{2}$ photolysis coefficients have not been compared during the vertical ascents since the differences are too important to make correlations. So the comparison is displayed for the whole flight period (Fig. 4).

\subsubsection{Carbon monoxide}

The CO concentrations were not very high on both days (around 140 or $120 \mathrm{ppbv}$ ) and the range of variations remained small in the whole boundary layer (along the stabilised legs, to the right of the dotted line). The Merlin-ARAT as well as the Dornier-ARAT comparison (diagrams A and B) are rather good in the boundary-layer. However, the ARAT (modified Thermo Electron: 30-s response time and 18-mn zero-set) is most of the time higher than the Dornier (AeroLaser: 1-s response time and 4-mn zero-set) (up to 10\%) and displays larger fluctuations, whereas in the first case, the sensor model is the same. Attention must be paid for the $\mathrm{CO}$ measurements during sounding flight sequences where the Merlin is $16 \%$ higher than the ARAT for instance (diagram A). They suggest that the humidity and pressure corrections applied to the Merlin measurements have to be revisited (characteristics inside the chamber cannot be reached). However, the ARAT whose measurement chamber is pressurized and for which water vapor is trapped exhibits the 
A

MERLIN-ARAT

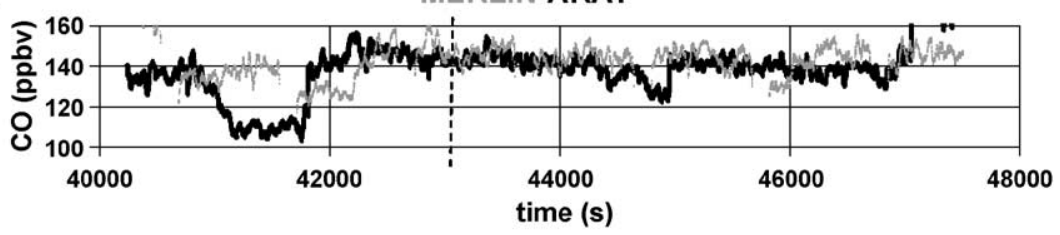

B

DORNIER-ARAT
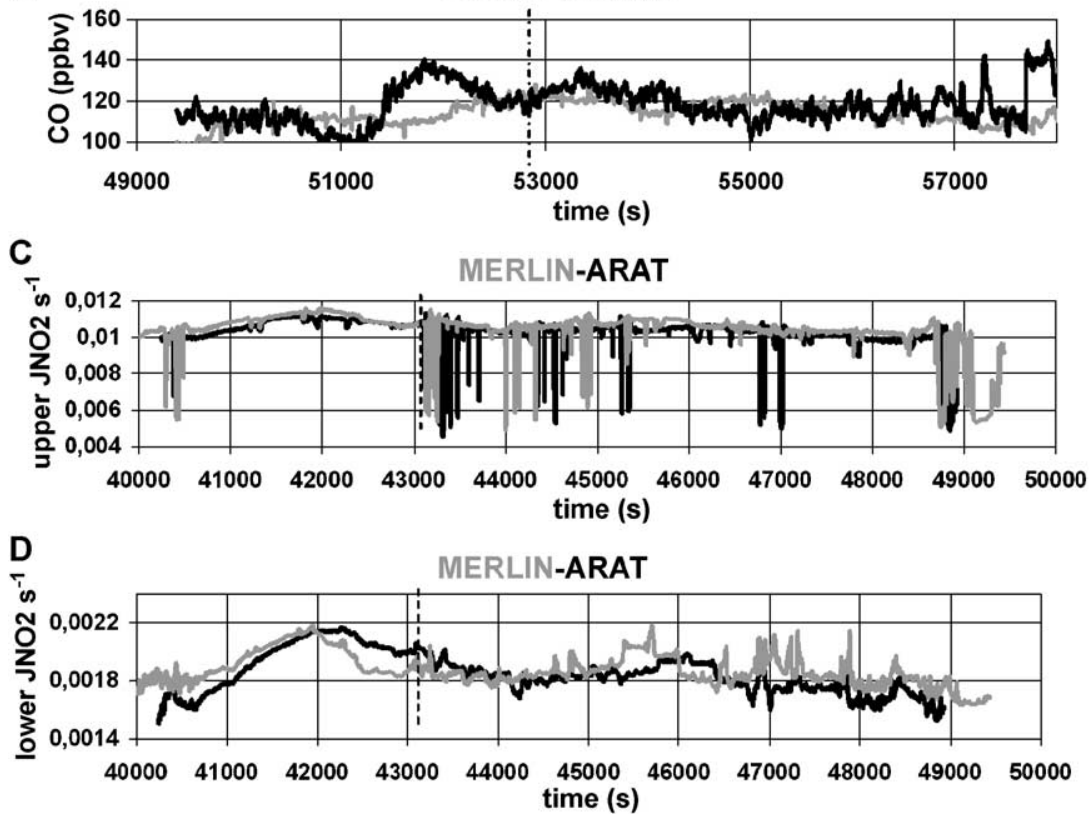

Fig. 4. Time series of the CO concentration for the Merlin-ARAT (A) and Dornier-ARAT flight (B) and $J_{\mathrm{NO}_{2}}$ photodissociation coefficients for the Merlin-ARAT flight (upper sensor in C and lower in D). The dashed line separates the sounding (left part) from the constant level measurements in the ABL (right part).

same defect around time $52000 \mathrm{~s}$ (diagram B). These results are poor in comparison to those of the in-flight comparison between the Dornier and the Partenavia aircraft operated by the Fraunhofer Institut für Atmosphärische Umweltforschung, Garmisch-Partenkirchen during the EVA 2 project in 1992 (Corsmeier et al., 2001). Both used an Aerolaser AL5001 CO. They reached agreement whatever the level to within $1.2 \%$ for a range of [250-400] ppbv, which is the same as the $\pm 5 \mathrm{ppbv}$ indicated for the sensor modified by the Laboratoire d'Aérologie.

For the data base, the $\mathrm{CO}$ results will be provided with a $10 \%$ uncertainty and no correction will be applied. Attention will have to be paid during the soundings for the Merlin and ARAT data. The Aztec was not equipped for CO measurements.

\subsection{2. $\mathrm{NO}_{2}$ into $\mathrm{NO}$ photolysis coefficient}

The time series of Fig. 4 (diagram C) shows the evolution of the upward $J_{\mathrm{NO}_{2}}$ of the Merlin and ARAT throughout the whole flight. Despite the numerous spikes, the values 
are found to be relatively close, with a maximum difference of $6.10^{-4} \mathrm{~s}^{-1}$ which corresponds to a 5\% relative accuracy. This is a little higher than the sensor accuracy (4\%). During the International Photolysis Frequency Measurement and Modeling Intercomparison (Shetter et al., 2003), various experimental techniques for $J_{\mathrm{NO}_{2}}$ measurement have been compared and found to match within a $10 \%$ uncertainty. As the sensor measuring the downward $J_{\mathrm{NO}_{2}}$ on the Merlin could not be calibrated in time, the time series over the whole flight presented in Fig. 4 (diagram D) have been obtained following a correlation between Merlin and ARAT values obtained along the lowest level leg, using the following regression line:

$$
J_{\mathrm{NO}_{2}}^{B}=758.5 J_{\mathrm{NO}_{2}}^{b}+1.5110^{-3}
$$

with ' $\mathrm{B}$ ' for the calibrated value (expressed in $\mathrm{s}^{-1}$ ), ' $\mathrm{b}$ ' for the raw value (expressed in V). The comparison is satisfactory within $1.3 \times 10^{-4} \mathrm{~s}^{-1}(7 \%)$. The highest difference occurs during the sounding part which is not surprising for a radiation parameter (Shetter et al., 2003). Anyway the 'calibration' against the ARAT had been on purpose done at constant level to avoid the sounding flight sequence.

\subsection{3. $\mathrm{NO}_{2}$ and $\mathrm{NO}$ measurements}

As said before, the MetAir $\mathrm{NO}_{x} \mathrm{TO}_{y}$ sensor did not work well on the Aztec and Merlin. The only results available for comparison are those from MONA and the Dornier modified $\mathrm{NO}_{x} \mathrm{TO}_{y}$. Unfortunately, the $\mathrm{NO}_{2}$ concentrations were very low on this not very polluted day: they remained around 1 ppbv with some peaks at 2 ppbv for the Dornier while the ARAT provided $0.5 \mathrm{ppbv}$ but larger peak values reaching $4 \mathrm{ppbv}$. NO concentrations were too low to be accurately detected (a few pptv with some peaks at $0.5 \mathrm{ppbv}$ ). So no conclusion can be drawn on this unique flight comparison.

\subsection{Wind measurement comparisons}

During the four legs devoted to wind measurement, the airplane flew at their nominal speed which induced a time shift in the measurements. So the results provided in this subsection have been set back in phase. They are displayed in a ground coordinate system whose origin is the point where the two trajectories are the closer. The wind vectors are averaged so as to represent only one point per kilometer. To make sure that the aircraft pairs have flown over the same area, the trajectories are then compared, together with the measurements of the relief height.

We chose to present only 6 comparisons (Fig. 5) among the 39 that were drawn, with a well-working case (diagram A) and an ill-working case (diagrams B and C). Diagram A corresponds to an upwind flight leg (P4) performed by the Dornier and ARAT at $800 \mathrm{~m}$. They flew over the same relief and measured exactly the same wind speed and direction with similarly fluctuations. This was made easier by the range of wind velocity that varies from 5 to $9 \mathrm{~ms}^{-1}$. Diagram B is a crosswind leg (P6) from Merlin and ARAT at $500 \mathrm{~m}$. In spite of the phase correction, a phase shift remains, as can been seen on the relief height indication. However this phase shift is not the only difference in the results that indicate a constant difference in the wind direction and some difference in the wind speed 

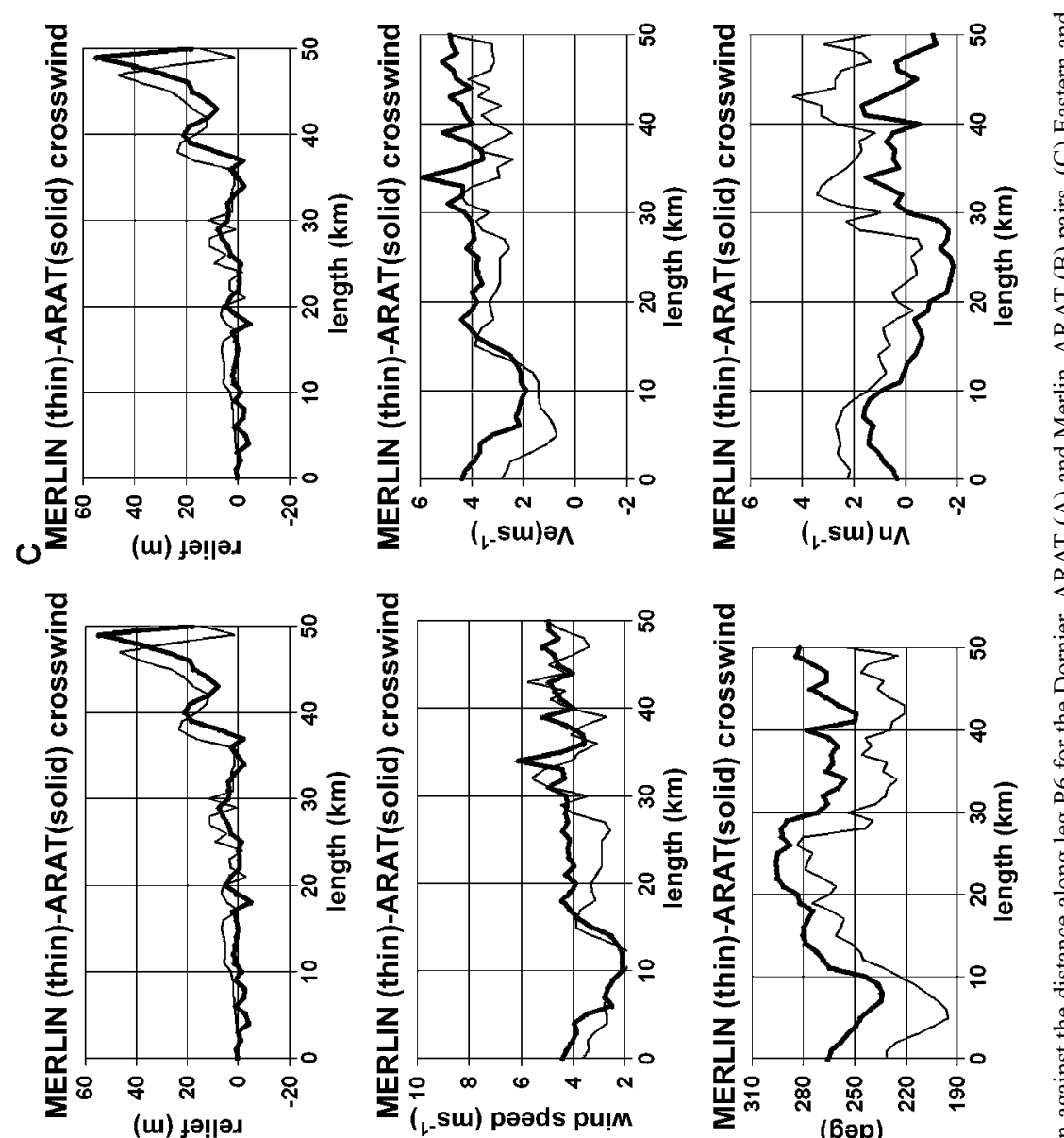

$\boldsymbol{m}$

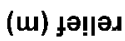
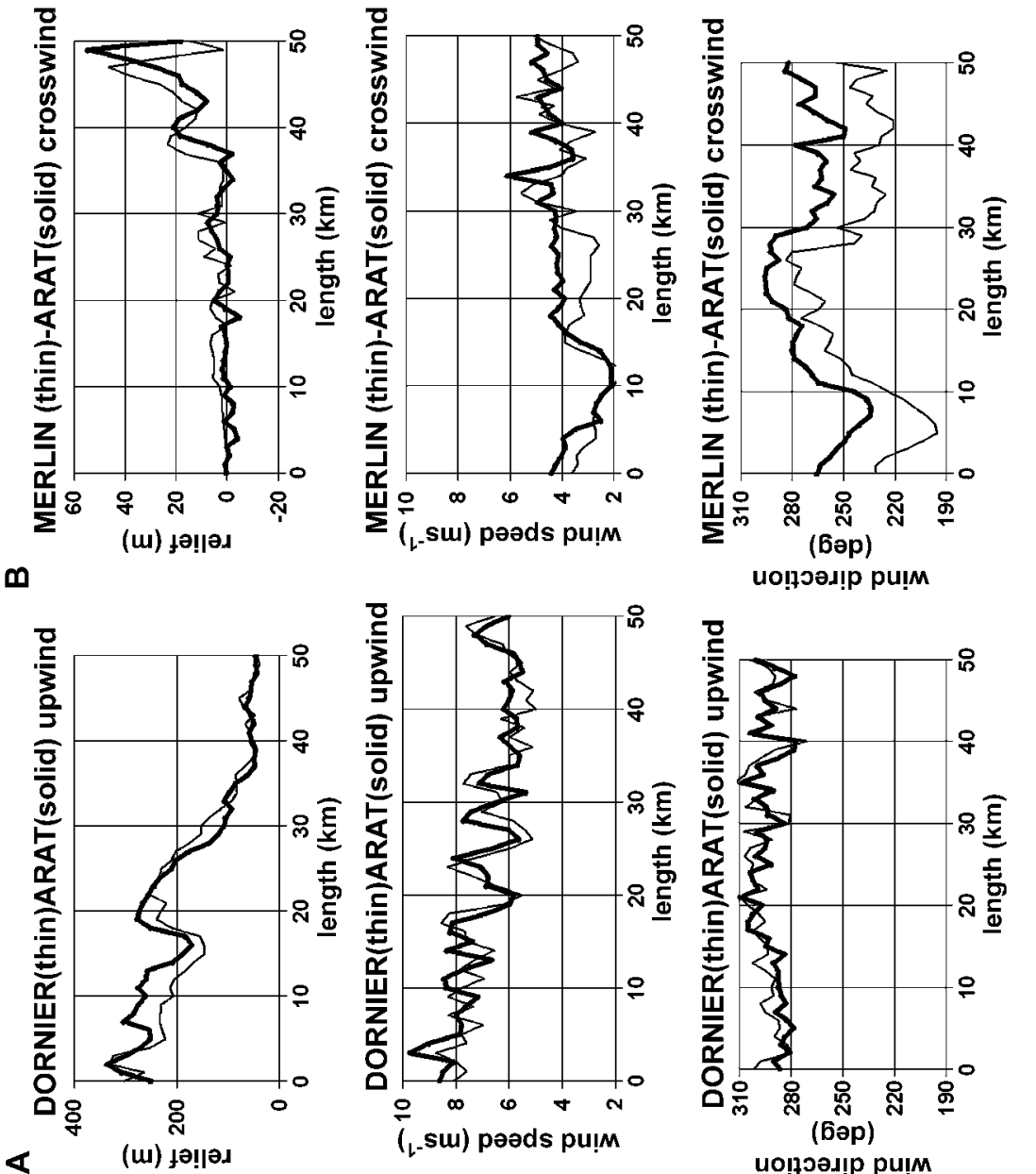

uo!̣วәд!p pu!m

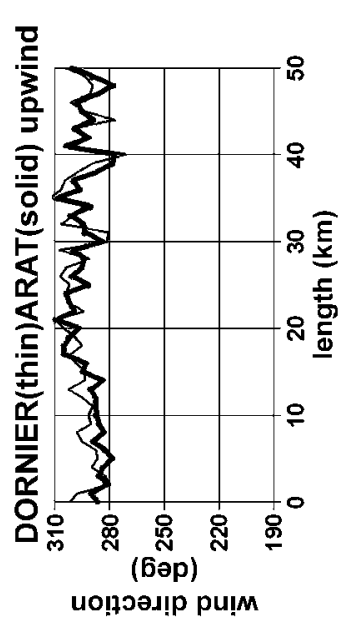

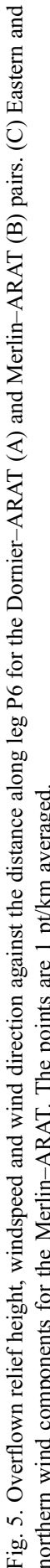


fluctuations. The wind is weak along this leg, so the comparison is also made using the eastern and northern components of the wind (diagram C). They indicate a $2-\mathrm{ms}^{-1}$ systematic overestimation of the Merlin in the crosswind direction and a $1-1.5-\mathrm{ms}^{-1}$ underestimation in the other direction. These values are high: they slightly compensate for the velocity but the difference can reach $30^{\circ}$ for the wind direction.

Table 4 displays the averages and standard deviations of the winds measured on each leg. The mean values are also compared in Fig. 6. The pairs Dornier-ARAT and DornierAztec match to within $\pm 0.9 \mathrm{~ms}^{-1}$ and $\pm 4^{\circ}$ (except for one case). The Merlin however displays significantly different values from those of the ARAT, even when the wind is not weak. The conditions when the differences between ARAT and Merlin are the highest are those of the legs parallel to the wind direction. Owing to the fact that both Dornier-Aztec and Dornier-ARAT comparisons are good, we must recognize there is a problem on the Merlin, particularly on the legs parallel to the wind. This suggests a problem on the true air speed since wind velocity measurements in the crosswind direction are less sensitive to the true air speed measurements.

Among the various errors that may be involved in the wind measurements, we investigated the possibility of the INS drifts. We compared information from GPS and INS for the wind velocity and obtained the raw results shown in Fig. $7(1 \mathrm{pt} / \mathrm{s})$. In spite of the noise on the GPS signal, the highest difference linked to the INS drifts is less than \pm 0.8 $\mathrm{ms}^{-1}$ on both components of the horizontal wind which does not explain the differences previously observed. As an indication, Quante et al. (1996) proposed corrections that could reach $2 \mathrm{~ms}^{-1}$.

As a conclusion on these wind measurements, no correction has been brought to the wind measurements of the four airplanes since the results are similar for ARAT, Aztec and Dornier and the problem is still under investigation on the Merlin. We will retain an accuracy of $0.9 \mathrm{~ms}^{-1}$ for the velocity and $4^{\circ}$ in direction for the three former airplanes. These results are similar to those from FIFE (MacPherson et al., 1992)(1 ms $\left.{ }^{-1}\right)$, EUCREX (Quante et al., 1996) $\left(1 \mathrm{~ms}^{-1}\right)$, and a little worse than those from SEMAPHORE (Lambert and Durand, 1998), where the Merlin was also involved $\left(0.5 \mathrm{~ms}^{-1}\right.$ and $\left.3.5^{\circ}\right)$.

\subsection{Radiation measurement comparisons}

Radiation measurements include the radiation flux in the shortwave and longwave spectral ranges. The P6 leg $(500 \mathrm{~m})$, which enabled the comparison of these parameters starts above the sea and ends up above land. A wide range of values is thus observed. The surface temperature measurements obtained with the Barnes or Heinman sensors are also compared.

Table 5 displays the mean values and standard deviations of the four radiation fluxes and of the surface temperature collected along the P6 leg. The mean values of the ARAT are lower than those of the Dornier for the four components, with a maximum of $17 \mathrm{~W} / \mathrm{m}^{2}$ (4\%) for the upward infrared. These differences compensate and the net fluxes are equivalent. The differences are less marked between the ARAT and the Merlin and do not reveal any systematic underestimation. However, the differences sum up which leads to an underestimation of $18 \mathrm{~W} / \mathrm{m}^{2}(5 \%)$ of the ARAT net flux compared with that of the Merlin.

The measurement differences obtained with the Heinman and Barnes devices on the P6 leg at $500 \mathrm{~m}$ are significant for both pairs of aircraft: 3 and $2{ }^{\circ} \mathrm{C}$. Similarly, if the 


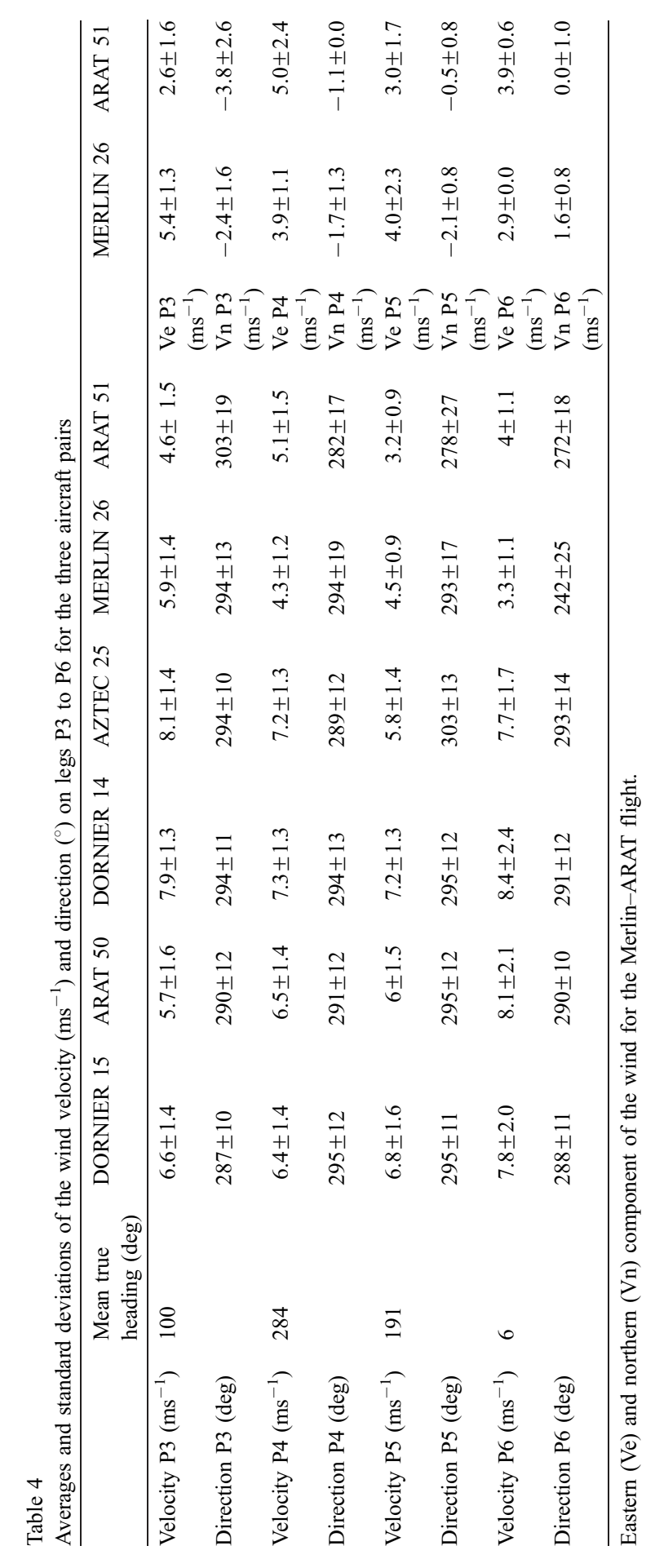




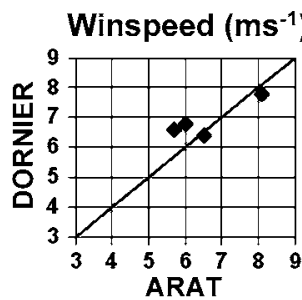

Wind direction

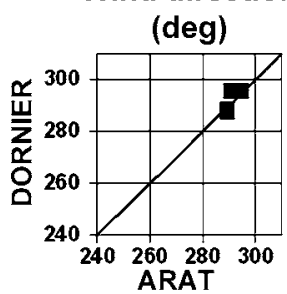

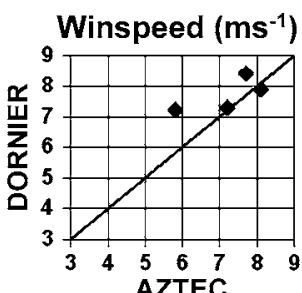

Wind direction

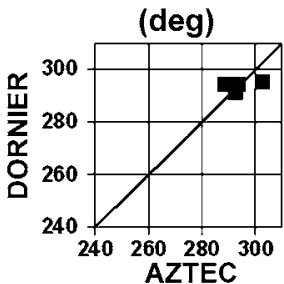

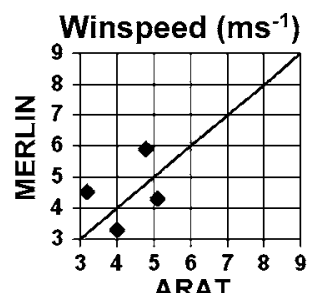

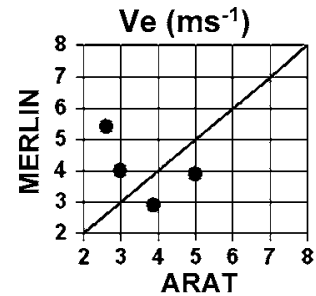

Wind direction

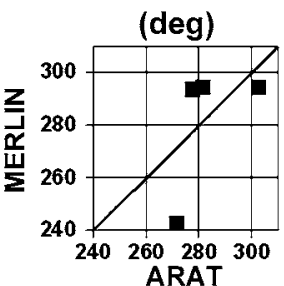

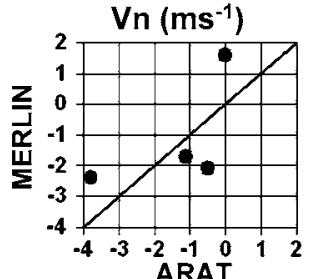

Fig. 6. Mean wind speed (diamonds), wind direction (squares) and horizontal wind components (circles) comparisons for the three pairs of flights $(1 \mathrm{pt} / \mathrm{km})$.

differences between the IR flux calculated from surface temperature are compared (with emissivity equal to unity), the results do not agree either: a $2{ }^{\circ} \mathrm{C}$ temperature difference between Merlin and ARAT corresponds to $13 \mathrm{~W} / \mathrm{m}^{2}$, measured with both Merlin and ARAT Barnes devices, whereas the upward IR pyrgeometers measure similar averages. The two Barnes devices information are retrieved using the same calibration coefficient, which is perhaps not correct. Between Dornier and ARAT, the differences of 17 and $18 \mathrm{~W} /$ $\mathrm{m}^{2}$ between both longwave sensors or surface temperature sensors are the same but of the opposite sign. So this comparison does not allow any conclusion.

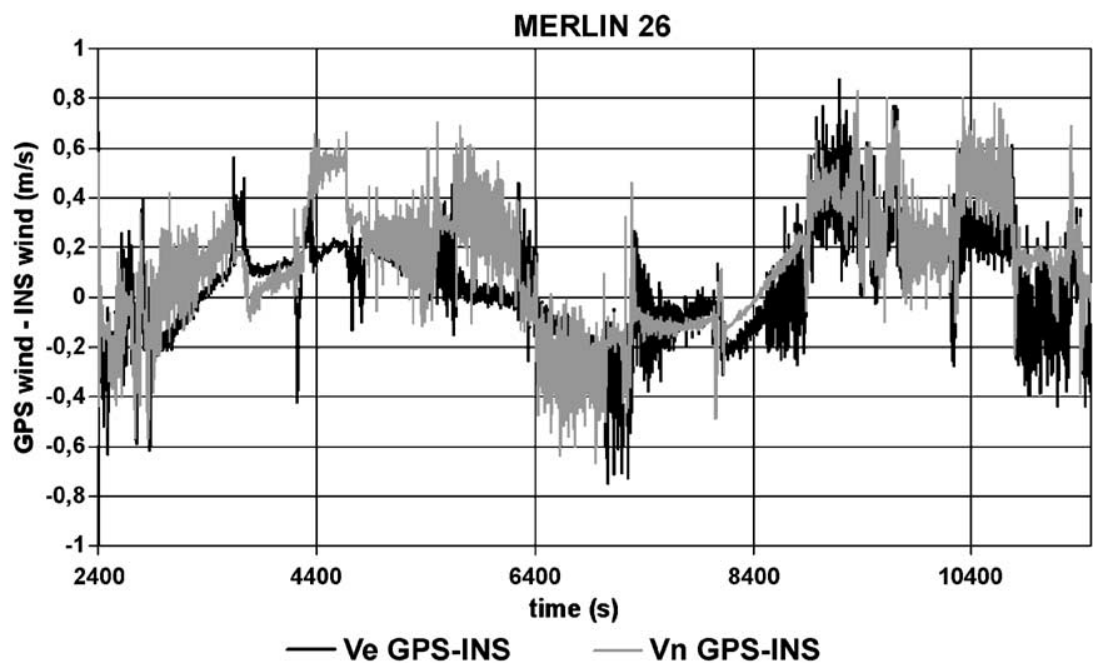

Fig. 7. Difference between GPS and INS wind components for the Merlin flight (1 pt/s). 
Table 5

Mean values and standard deviations of the radiation fluxes and of the surface temperature measured by each aircraft and difference between two aircraft, along P6 leg at $500 \mathrm{~m}$

\begin{tabular}{lcccccr}
\hline & ARAT 50 & Dornier 15 & $\begin{array}{c}\text { ARAT- } \\
\text { Dornier }\end{array}$ & ARAT 51 & Merlin 26 & $\begin{array}{r}\text { ARAT- } \\
\text { Merlin }\end{array}$ \\
\hline Shortwave $\downarrow\left(\mathrm{W} / \mathrm{m}^{2}\right)$ & $514 \pm 84$ & $530 \pm 82$ & -16 & $902 \pm 24$ & $901 \pm 15$ & 1 \\
Shortwave $\uparrow\left(\mathrm{W} / \mathrm{m}^{2}\right)$ & $73 \pm 26$ & $83 \pm 30$ & -10 & $106 \pm 40$ & $116 \pm 47$ & -10 \\
Longwave $\downarrow\left(\mathrm{W} / \mathrm{m}^{2}\right)$ & $330 \pm 11$ & $336 \pm 10$ & -6 & $341 \pm 8$ & $336 \pm 6$ & 5 \\
Longwave $\uparrow\left(\mathrm{W} / \mathrm{m}^{2}\right)$ & $436 \pm 10$ & $453 \pm 9$ & -17 & $444 \pm 12$ & $445 \pm 13$ & -1 \\
Surface temperature $\left({ }^{\circ} \mathrm{C}\right)$ & $29 \pm 2$ & $26 \pm 3$ & 3 & $31 \pm 4$ & $33 \pm 5$ & -2 \\
Surface radiance & 472 & 454 & 18 & 485 & 498 & -13 \\
$\quad\left(\mathrm{~W} / \mathrm{m}^{2} ; \varepsilon=1\right)$ & & & & & $676 \pm 61$ & 18 \\
Net radiation $\left(\mathrm{W} / \mathrm{m}^{2}\right)$ & $335 \pm 81$ & $330 \pm 83$ & 5 & $694 \pm 62$ & & \\
\hline
\end{tabular}

In addition, we also noted a very important difference between Dornier and ARAT surface temperatures above the sea $\left(5^{\circ} \mathrm{C}\right.$ ) (not shown here) and only $1{ }^{\circ} \mathrm{C}$ between the Merlin and ARAT both measuring with Barnes devices. A comparison of these results to those provided by channel 4 IR of the NOAA-AVHRR satellite over the sea (without any atmospheric correction) showed that the Barnes surface temperature is about $5{ }^{\circ} \mathrm{C}$ too warm , which closely corresponds to the overestimation relative to the Dornier. We will consider in the following the Dornier surface temperature as a reference temperature, at least above the sea. This difference becomes smaller above land between Dornier and ARAT $\left(2{ }^{\circ} \mathrm{C}\right.$ on average $)$ and remains the same between Dornier and Merlin $\left(4{ }^{\circ} \mathrm{C}\right)$ above sea or ground.

To conclude, the minor differences observed on the measurements of the radiation flux components may be ignored since the net fluxes are sensibly equivalent. For the surface temperature, we obtained differing results with overestimated ARAT and Merlin surface temperatures values. No correction will be applied but it will be kept in mind that the Dornier measurements are good, at least over the sea, that the Merlin is $4{ }^{\circ} \mathrm{C}$ too warm over sea and over land, and the ARAT $5{ }^{\circ} \mathrm{C}$ too warm over sea and $2{ }^{\circ} \mathrm{C}$ over land. Our resulting accuracy is far under the range indicated by MacPherson et al. (1992) for FIFE who reported differences of several tens of $\mathrm{Wm}^{-2}$ on the incident flux, but far too high for the surface temperature.

\section{Turbulence study}

\subsection{Problem of turbulence measurements during ESCOMPTE}

The following remarks are going to highlight the difficulty to compute turbulent fluxes during the ESCOMPTE experiment and explain why only variances were provided to the data base. However, turbulent data can be useful to quantify the heterogeneity, and the turbulent moments may be used to study the exchanges inside the atmospheric boundary-layer and at the boundary-layer top. That is why the turbulence measurements were also compared during the intercomparison flights, by choosing 'idealized' flight sections. 
The turbulence measurements computed at $25 \mathrm{~Hz}$ on the Merlin and Dornier and 16 $\mathrm{Hz}$ on the ARAT, usually enable the calculation of the sensible heat flux $\mathrm{H}$, latent heat flux LE and momentum flux $\tau$, by using the eddy correlation method which consists in computing the covariance $\overline{w^{\prime}} x^{\prime} \quad\left(w^{\prime}\right.$ is the vertical velocity fluctuation and $x^{\prime}$ the scalar fluctuation) on an interval long enough to integrate a sufficient number of turbulent events. Typically, the integration length must be at least 10 times the characteristic wavelength $\lambda_{\mathrm{w}}$ (wavelength of the maximum of the vertical velocity spectrum, which is assimilated to the wavelength of the largest eddies of the turbulence field). For this method to apply, the turbulent functions must be stationary, for instance as those represented in Fig. 8 (diagram A) (ARAT flight leg P9 at $160 \mathrm{~m}$, obtained with the ARAT above the Crau plain). The integral of the covariance function, represented in the central row, is then almost linear (in spite of some steps occurring in the integral), showing that the sampling is statistically representative: we will consider this case as homogeneous (knowing however there are better references for homogeneity especially over the sea).

Another example of functions, which is unfortunately more typical of the ESCOMPTE data, is represented in Fig. 8 (diagram B). It shows the functions over the same area, with the opposite heading and at $470 \mathrm{~m}$ (P8). There the turbulence is no longer homogeneous. The reasons of the frequent inhomogeneity encountered during ESCOMPTE are numerous:

- For a correct measurement of the turbulent parameters, the aircraft must be stabilised in speed, heading and attitude. It thus flies along horizontal legs, whose minimum level is close to the highest terrain elevation. This minimum level was $800 \mathrm{~m}$, which meant that the aircraft flew $800 \mathrm{~m}$ above the plains, but only about a hundred meters above the highest ridges. The height in the boundary layer not being constant, the functions could not be homogeneous.

- Added to this flight level problem, the complexity of the ground topography entails local flow phenomena or slope effects which disturb the transfers. Furthermore, the region is submitted to complex wind regimes (synoptical, sea and lake breeze) whose interactions have incidence on the homogeneity. Moreover, the wind is often weak, which increases the lack of stationarity.

- The boundary layer was often relatively thin due to frequent sea-breeze conditions. It could be very low close to the sea (300 to $500 \mathrm{~m}$ like in the work of Puygrenier et al., this issue, or Delbarre et al., this issue) or larger like over the Durance valley (1200 m or more, Cousin et al., this issue). So during the typical flight sequence which consisted in flying constant level legs to describe the variability of dynamics and chemistry over the area, several flight sequences were flown above the boundary layer.

Because of all these sources of heterogeneity, it is impossible to study the ESCOMPTE turbulence with the usual tools adapted to homogeneous turbulence. The aim is not to develop this point here but to try to check the matching between turbulent measurements of the aircraft. For this comparison, we tried to find a relatively homogeneous area, to be able to compare moments and spectral characteristics. Only two flight legs were used, which we know is insufficient for a statistical study. 

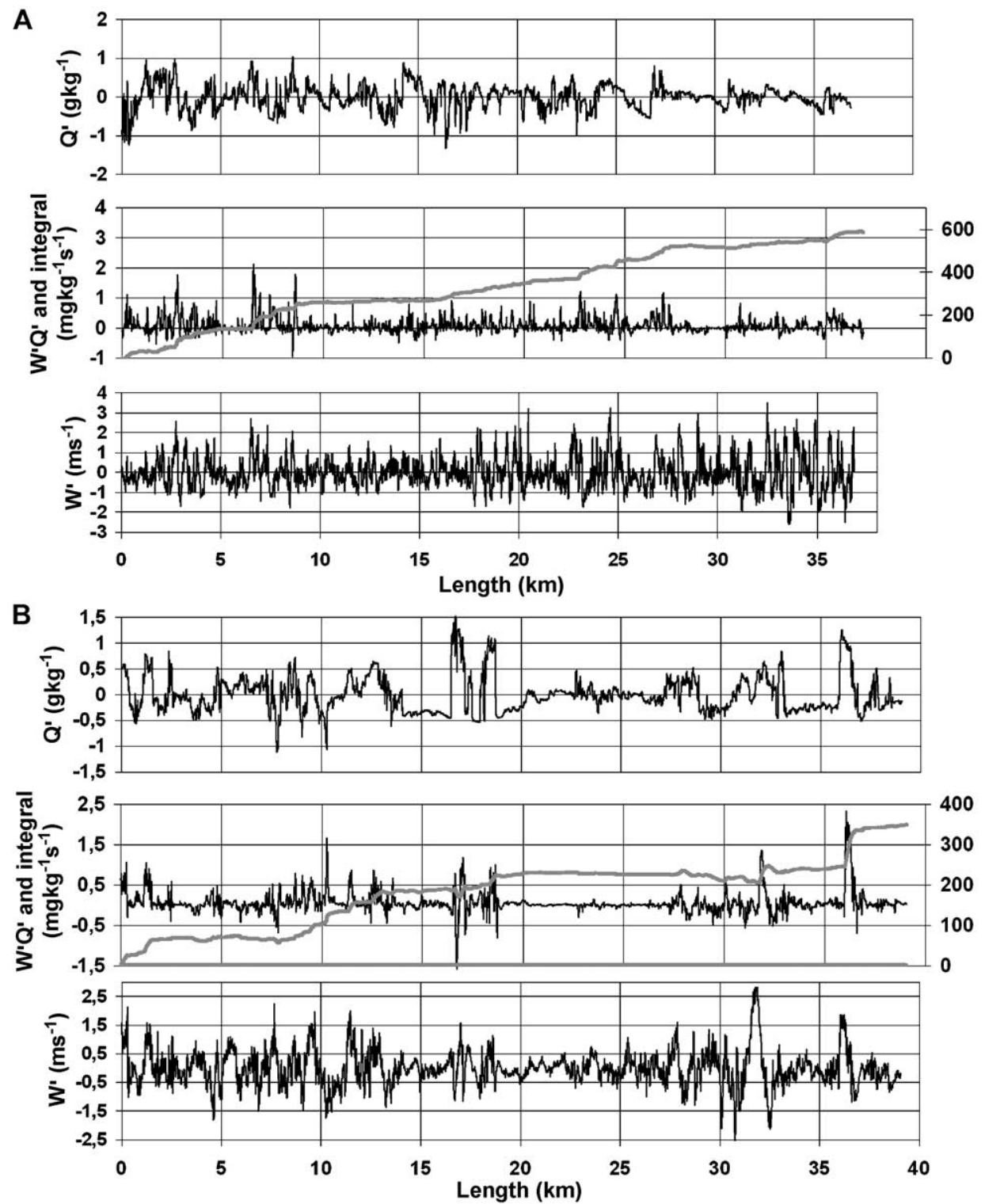

Fig. 8. (A) (from top to bottom): Time series of high-pass filtered water vapor content fluctuations $Q^{\prime}$, covariance $W^{\prime} Q^{\prime}$ and cumulated covariance, and vertical velocity $W^{\prime}$, for leg P9 at $160 \mathrm{~m}$ for ARAT 51. (B) Same as A but for leg P8 at $470 \mathrm{~m}$.

\subsection{Turbulence comparison}

The results compared are legs P8 and P9 of the Merlin-ARAT and Dornier-ARAT flights (Fig. 1). No additional vertical exploration had been performed over the Crau during 
the intercomparison flight, and we had considered that $470 \mathrm{~m}$ would have been in the middle of the boundary layer (middle of a clear day in June, with no sea-breeze). Unfortunately, measurements showed we were wrong and that the higher level leg was flown at the boundary-layer top.

The results of the turbulent moments, characteristic scales, and dissipation rates are compared in Table 6 for the Merlin-ARAT and Dornier-ARAT pairs. The column entitled "difference" corresponds to the ratio of the difference to the geometrical average (|aircraft1 $\left.\right|^{*} \mid$ aircraft $\left.2 \mid\right)^{1 / 2}(||$ is used for absolute value). The functions were high-pass filtered with a constant cut-off frequency of $0.018 \mathrm{~Hz}$ (which corresponds here, to wavelengths of 5.5, 5.1 and $4.2 \mathrm{~km}$ for the Merlin, ARAT and Dornier respectively). In those conditions, the loss due to filtering, which is the ratio (in \%) of the (raw flux-filtered flux) to the raw flux, is a means to evaluate the contribution of the low frequencies, which often indicates the heterogeneity of the functions.

According to Bernard-Trottolo et al. (2004), the lost due filtering is usually $10 \%$ to $15 \%$ at the most for homogeneous legs (usually at boundary-layer bottom). It may reach very high values (up to $100 \%$ ) when reaching boundary-layer top. As could be expected from the functions presented in Fig. 8, the loss due to filtering is relatively significant for the three fluxes on the $470 \mathrm{~m}$ legs. It is here about $30 \%$ for $\mathrm{H}, 20-35 \%$ for LE and $19-25 \%$ for $\tau$. This loss due to filtering is however surprisingly still high or even higher for the $160 \mathrm{~m}$ leg: $42-55 \%$ and $45-50 \%$ for $\mathrm{H}$ and $\tau$, respectively (the largest differences are highlighted in Table 6). This means that this low level is not so homogeneous (as seen before with the steps on the covariance integral).

The following discussion concerns (except when mentioned) the filtered values only. They are shown in bold characters in Table 6 . The sensible heat fluxes at $470 \mathrm{~m}$ are weak and sometimes negative, which indicates that they were measured in the entrainment layer. The accuracy of the computation can be very bad, even meaningless at the top of the boundary layer where the sensible heat flux is very low. The sample leg should be lengthen under these conditions (not possible since the plain is not so large). Results in LE and $\tau$ also reflect some heterogeneity but indicate a difference of $31-36 \%$ and $71-29 \%$, respectively, which is high but expected at this level in the boundary layer. Despite the apparent improvement of the homogeneity of the functions between the 470- and 160-m levels, the differences obtained on the fluxes are sometimes very high on the low level legs especially between the Dornier and ARAT where the difference always exceed $45 \%$ and may reach $95 \%$ for the momentum.

Concerning the variances, the results are comparable, except for the vertical windspeed on P8, and for the longitudinal windspeed on P9 at low level, for the Merlin-ARAT flight. The fact that in most cases, the variance comparison is better than the flux one may suggest a difference in the correlation coefficients. They have not been compared here.

Notes to Table 6:

Irregular values are highlighted and filtered values are in bold characters. $Z=$ leg altitude. Raw=raw value, filtered=high-pass filtered. Flux: $H=$ sensible heat flux, LE=latent heat flux, $u^{*}=$ friction velocity. 2 nd order moments: var $W, U, V, T, Q=$ variance of vertical, longitudinal and transversal components of the wind velocity, potential temperature, water vapor content. TKE $=\frac{1}{2}\left(u^{i^{2}}+v^{v^{2}}+w^{\bar{j}}\right.$. $)$ Lambda $=\lambda \mathrm{w}$ : length scale corresponding to the maximum value of the vertical velocity spectrum. Eps: dissipation rates of turbulent kinetic energy and half variance of temperature and humidity. 


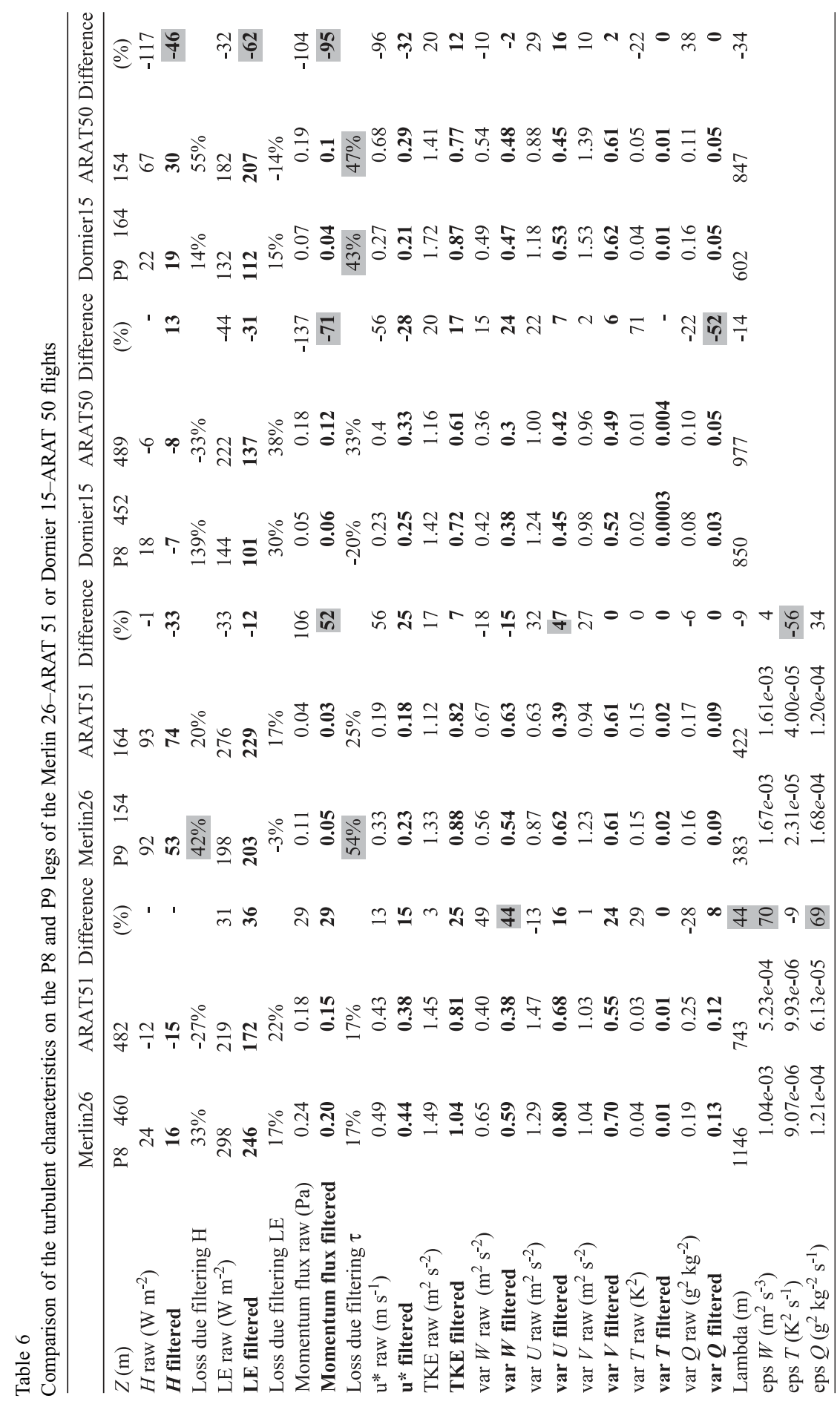


The dissipation rates of turbulent kinetic energy $(\varepsilon)$ and of temperature or humidity halfvariances $\left(\varepsilon_{T}\right.$ and $\left.\varepsilon_{Q}\right)$ were computed from the highest frequency part of the spectra, that is between $1 \mathrm{~Hz}$ and the Nyquist frequency $(12$ and $8 \mathrm{~Hz}$ for the Merlin and the ARAT, respectively). The results display differences of $70 \%, 54 \%$ and $69 \%$ for the three parameters $W, T$ and $Q$. Lambert and Durand (1998) indicate better results for the intercomparison of $\varepsilon$ during the SEMAPHORE experiment with a matching within $20 \%$ in the marine boundary layer.

We also compared $\varepsilon, \varepsilon_{\mathrm{T}}$ and $\varepsilon_{\mathrm{Q}}$ on all the sequences of the comparison flight, including the sounding (Fig. 9). The correlations are good (about 0.9) but it is clear that for temperature, for instance, the line is far from the 1:1 slope. In fact, these results heavily depend on the quality of the spectrum in the inertial subrange (slope and noise). The highfrequency behavior of the ARAT and Merlin energy spectra has been checked through the comparison of the spectrum slope in the inertial subrange (Fig. 10). The points corresponding to the low level (empty symbols) are close to the 1:1 slope, except for humidity, that drops too much, for Merlin as well as ARAT (slope around -2). On the
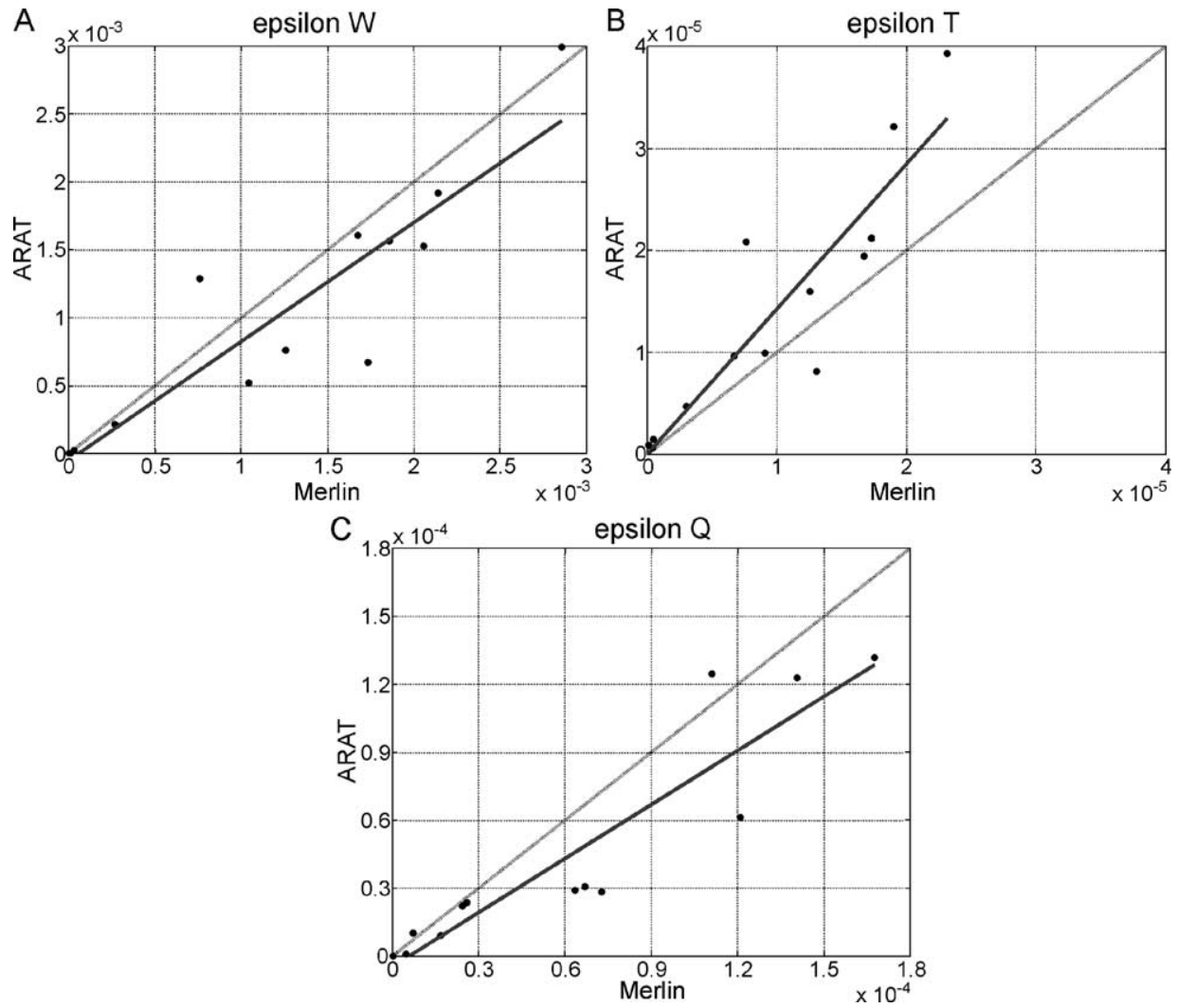

Fig. 9. Comparison between Merlin and ARAT of the dissipation rates of turbulent kinetic energy $\left(\mathrm{m}^{2} \mathrm{~s}^{-3}\right)$ (epsilon $W$ ), of half temperature variance $\left(\mathrm{K}^{2} \mathrm{~s}^{-1}\right)$ (epsilon $T$ ) and half humidity variance $\left(\mathrm{g}^{2} \mathrm{~kg}^{-2} \mathrm{~s}^{-1}\right)$ (epsilon $Q$ ) for the different legs and vertical exploration section, with regression (black) line and 1:1 slope (grey line). 


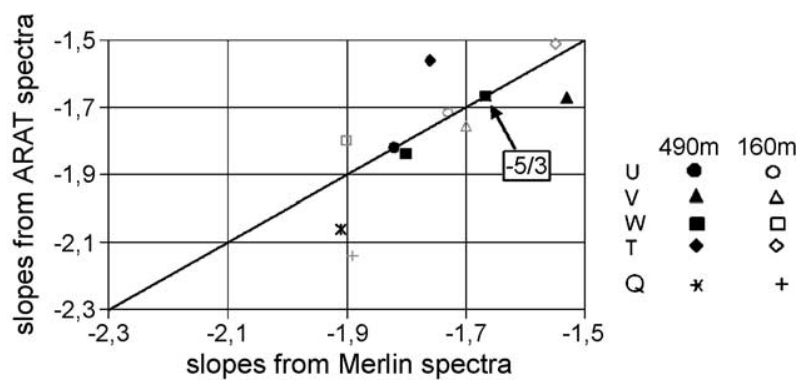

Fig. 10. Comparison of the ARAT/Merlin spectrum slopes in the inertial subrange.

opposite, the absolute values of the temperature spectrum slopes are smaller than $5 / 3$ (around 1.5-1.6). This point will have to be tightly checked in the other flights of the campaign. The Rosemount sensor is usually good up to $10 \mathrm{~Hz}$. The spectra that best match the theoretical $-5 / 3$ value are those of the velocity components, whatever the aircraft.

Two flight legs are not sufficient to draw a general conclusion on the turbulence during ESCOMPTE. However, we suggest that the turbulence user perform a statistical spectrum study of turbulence (to withdraw erroneous samples), use the same wavelength for highpass filtering, check the slopes in the inertial subrange, smooth the data with the same algorithm on the three aircraft.

\section{Conclusion}

This work enabled a comparison of the dynamic, thermodynamic, radiation, and gas trace measurements obtained at low $(1 \mathrm{pt} / \mathrm{s})$ and fast $(16$ or $25 \mathrm{pts} / \mathrm{s})$ rates. This comparison was performed by four airplanes flying by pairs: Dornier-Aztec, Dornier-ARAT, and Merlin-ARAT during ESCOMPTE 2001 to harmonize the data before including them in the database and to provide an accuracy range for each parameter. Much of this effort was focused on the mean parameters. The conclusion that can be drawn from this study is that the comparisons are remarkably close. We propose some improvements but emphasize that these are minor. Table 7 sums up the corrections suggested and offers some comments. The stated uncertainty is the maximal value of the discrepancy encountered for the range of the parameters measured during the three intercomparison flights. This is, in most cases, an overestimation of the uncertainty.

We must point out that improvements will have to be done in further experiments on the $\mathrm{CO}$ for which the overall uncertainty is higher than in the literature (particularly during vertical explorations). The measure of $\mathrm{NO}_{x}$ will also have to be improved, although the intercomparison flights did not allow concluding, since the concentrations were very low during this period. We will highlight the result that Dornier, ARAT and Aztec wind comparisons are very similar, which is important in this area of low and highly varying wind. The confidence that we can impute to those measurements in such heterogeneous conditions will be a powerful tool to test models. Turbulence will be also a good means of investigating the heterogeneity but this will require a thorough analysis of the turbulent 
Table 7

Accuracies of the measurements (bold characters) for each parameter studied

\begin{tabular}{|c|c|c|c|c|}
\hline & ARAT & AZTEC & DORNIER & MERLIN \\
\hline Wind direction (deg) & 4 & 4 & 4 & $\begin{array}{l}\text { to be further } \\
\text { investigated }\end{array}$ \\
\hline Wind velocity $\left(\mathrm{ms}^{-1}\right)$ & 0.9 & 0.9 & 0.9 & $\begin{array}{l}\text { to be further } \\
\text { investigated }\end{array}$ \\
\hline Temperature $\left({ }^{\circ} \mathrm{C}\right)$ & $\begin{array}{l}\text { 0.4; Rosemount } \\
\text { classical: } a=0.9933 \text {, } \\
b=-0.205\end{array}$ & $\begin{array}{l}\text { 0.4; Rosemount } \\
\text { classical: } a=1.0359 \text {, } \\
b=0.113\end{array}$ & 0.4 & 0.3 \\
\hline $\begin{array}{l}\text { Water vapor } \\
\text { content }\left(\mathrm{g} \mathrm{kg}^{-1}\right)\end{array}$ & 0.3 & 0.3 & $\begin{array}{l}\mathbf{0 . 3} ; a=1.047 \\
b=-0.904\end{array}$ & 0.3 \\
\hline Ozone (ppbv) & $\begin{array}{l}5 \text { ckeck climb } \\
\text { and sink rates }\end{array}$ & $\begin{array}{l}5 \text { take with } \\
\text { caution during } \\
\text { ascents and descents }\end{array}$ & $\begin{array}{l}5 \text { ckeck climb } \\
\text { and sink rates }\end{array}$ & $\begin{array}{l}5 \text { ckeck climb } \\
\text { and sink rates }\end{array}$ \\
\hline $\begin{array}{l}\text { Carbon monoxide } \\
\text { (ppbv) }\end{array}$ & 10 & - & 10 & 10 \\
\hline Net flux $\left(\mathrm{Wm}^{-2}\right)$ & 18 & - & 5 & 18 \\
\hline $\begin{array}{l}\text { Surface temperature } \\
\quad\left({ }^{\circ} \mathrm{C}\right)\end{array}$ & $\begin{array}{l}5{ }^{\circ} \mathrm{C} \text { too warm } \\
\text { over sea. } \\
2{ }^{\circ} \mathrm{C} \text { over ground }\end{array}$ & - & correct & $\begin{array}{l}4{ }^{\circ} \mathrm{C} \text { too warm } \\
\text { over sea }\end{array}$ \\
\hline$J_{\mathrm{NO}_{2}}$ upward $\left(\mathrm{s}^{-1}\right)$ & $6 \times 10^{-4}$ & - & - & $6 \times 10^{-4}$ \\
\hline $\begin{array}{c}J_{\mathrm{NO}_{2}} \text { downward }\left(\mathrm{s}^{-1}\right) \\
(\text { raw value in } \mathrm{V})\end{array}$ & $1.3 \times 10^{-4}$ & - & - & $\begin{array}{l}\mathbf{1 . 3} \times \mathbf{1 0}^{-\mathbf{4}} \\
a=758.5 \\
b=1.51 \times 10^{-3}\end{array}$ \\
\hline
\end{tabular}

The corrections proposed are presented as: corrected parameter $=a \cdot$ present parameter $+b$, with $a$ and $b$ given in the table.

functions, since the usual statistical methods (as the calculation of fluxes with the eddy correlation method) are likely to fail. This is not due to the quality of the measurements but to the fact that the assumptions of stationarity and spatial homogeneity will be most of the time not fullfilled during the ESCOMPTE experiment.

\section{Acknowledgements}

We particularly thank all the pilots, engineers, technicians and scientists who contributed during ESCOMPTE to the success of the flights, especially Marie-Pierre Lefebvre, François Goyon, Rémi Caillou, Christian Abonnel, Marc Laurens, Hubert Bellec, Frédéric Pouvesl, Jean Claude Etienne, Gilles Vergez, Didier Bernard, Marc Pontaud from Le Centre d'Aviation Météorologique-Météo France, Michel Charpentier and Frédéric Marin from Météo France, Bruno Piguet and Arnaud Méquignon from CNRM-Météo France (Centre National de Recherches Météorologiques), Christian Allet, Guy Penazzi, André Gribkoff, Noël Grand and Emmanuelle Breton from la Division Technique de l'INSU, Jean Claude Lostec, Daniel Damien and Jean-Luc Pilotto from l'Institut Géographique National, David Coscia from Laboratoire Inter-Universitaire des Systèmes Atmosphériques, Aimé Druilhet, Philippe Nédélec, Sandrine Bernard from Laboratoire d'Aérologie as well as B. Cros (Laboratoire d'Aérologie), and P. Durand 
(Météo France) who organized the campaign. The IMK (Institut für Meteorologie und Klimaforschung in Karlsruhe), and the CAATER (Coordinated Access to Aircraft for Transnational Environmental Research) program also supported ESCOMPTE and have to be thanked. Finally, we are grateful to the French scientific committee for research aircraft and again to the IMK that provided the financial support for the aircraft intercomparison flights. The first author would like to share special thoughts with those who will not any longer work with the Merlin and ARAT they loved: the ARAT performed its last scientific flight during ESCOMPTE and the Merlin has also stopped its scientific life since ESCOMPTE!

\section{References}

Bernard-Trottolo, S., Druilhet, A., Saï, F., Campistron, B., 2004. TRAC98: detection of coherent structures in a convective boundary layer using airborne measurements. Boundary Layer Meteorology 111 (2), 181-224.

Brümmer, B., 1993. ARKTIS 1993: Field report-Meteorologisches Institut, Universität Hamburg. Berichte aus dem Zentrum für Meeres-und Klimaforschung, Reihe A 11 (270 pp.).

Corsmeier, U., Hankers, R., Wieser, A., 2001. Airborne turbulence measurements in the lower troposphere onboard the research aircraft Dornier 128-6, D-IBUF. Meteorologische Zeitschrift 10 (4), 315-329.

Corsmeier, U., Kalthtoff, N., Vogel, B., Hammer, M.U., Fiedler, F., Kottmeier, CH., Volz-Thomas, A., Konrad, S., Glaser, K., Neininger, B., Lehning, M., Jaeschke, W., Memmersheimer, M., Rappenglück, B., Jakobi, G., 2002. Ozone and PAN formation inside and outside of the Berlin plume. Process analysis and numerical process simulation. Journal of Atmospheric Chemistry 42, 289-321.

Cousin, F., Tulet, P., Rosset, R., 2004. Interaction between local and regional pollution during Escompte 2001: impact on surface ozone concentrations (IOP2a and IOP2b). Atmos. Res. 74, 117-137 (this issue).

Cros, B., Durand, P., Cachier, H., Drobinski, Ph., Frejafon, E., Kottmeïer, C., Perros, P., Peuch, V.H., Ponche, J.L., Robin, D., Saï, F., Toupance, G., Wortham, H., 2004. The ESCOMPTE program: an overview. Atmospheric Research 69, 241-279.

Delbarre, H., Augustin, P., Saïd, F., Campistron, B., Benech, B., Lohou, F., Puygrenier, V., Moppert, C., Cousin, F., Fréville, P., Fréjafon, E., 2004. Ground-based remote sensing observation of the complex behaviour of the Marseille boundary layer during ESCOMPTE. Atmos. Res. 74, 403-433 (this issue).

Dobosy, R.J., Crawford, T.L., Mac Pherson, J.I., Desjardins, R., Kelly, R.D., Oncley, S.P., Lenschow, D.H., 1997. Intercomparison among four flux aircraft at BOREAS in 1994. Journal of Geophysical Research 102 (D24), $29101-29111$.

Druilhet, A., Durand, P., 1997. Experimental investigation of atmospheric boundary layer turbulence. Atmospheric Research 43, 345-388.

Gerbig, C., Schmitgen, S., Kley, D., Voltz-Thomas, T., 1999. An improved fast-response vacuum-UV resonance fluorescence CO instrument. Journal of Geophysical Research 104 (D1), 1699-1704.

Grunwald, J., Kalthoff, N., Fiedler, F., Corsmeier, U., 1998. Application of different flight strategies to determine areally averaged turbulent fluxes. Contributions to Atmospheric Physics 71, 283-302.

Güsten, H., Heinrich, G., Schmidt, R.W.H., Schurath, U., 1992. A novel ozone sensor for direct eddy flux measurements. Journal of Atmospheric Chemistry 14, 73-84.

Hankers, R., 1989. The equipment of a research aircraft with emphasis on meteorological experiments. Society of Flight Test Engineers, Reno, USA, 20th Annual Symposium proceedings, 7 pp., 18-21 September, Proceedings, 6.3-1-6.3-7.

Hutchinson, G.L., Yang, W.X., Andre, C.E., 1999. Overcoming humidity dependence of the chromium trioxide converter used in Luminol based nitric oxide detection. Atmospheric Environment 33, 141-145.

Kalthoff, N., Corsmeier, U., Schmidt, K., Kottmeier, C., Fiedler, F., Habram, M., Slemr, F., 2002. Emissions of the city of Augsburg determined using the mass balance method. Atmospheric Environment 36 (Suppl. No. 1), $19-31$.

Lambert, D., Durand, P., 1998. Aircraft to aircraft intercomparison during SEMAPHORE. Journal of Geophysical Research 103 (C11), 25109-25123. 
Lefebvre, M.P., Anne-Morera, M., Etienne, J.C., 1999. Incertitude sur les paramètres de base mesurés sur le Merlin IV: Note du Centre d'Aviation Météorologique No. 21, Météo-France.

Lenschow, D.H., 1986. Aircraft measurements in the boundary layer. In: Lenschow, D.H. (Ed.), Probing the Atmospheric Boundary Layer. Am. Meteorol. Soc, Boston, Mass, pp. 39-56.

Lipp, A., Speckels, S., Vieweg, 1995. Flight test results using an integrated navigation system in mountainous terrain.: ISPA 95, International symposium on precision approach and automatic landing, Braunschweig, Germany. Proceedings, Deutsche Gesellschaft für Ortung und navigation, pp. 205-211.

MacPherson, J.I., Grossman, R.L., Kelly, R.D., 1992. Intercomparison results for FIFE flux aircraft. Journal of Geophysical Research 97 (D17), 18499-18514.

Marion, T., Perros, P.E., Losno, R., Steiner, E., 2001. Ozone production efficiency in savanna and forest areas during EXPRESSO experiment. Journal of Atmospheric Chemistry 38 (1), 3-30.

Nedelec, P., Cammas, J.P., Thouret, V., Athier, G., Cousin, J.M., Legrand, C., Abonnel, C., Lecoeur, F., Cayez, G., Marizy, C., 2003. An improved infra-red carbon monoxide analyser for routine measurements aboard commercial airbus aircraft: technical validation and first scientific results of the MOZAIC III program. Atmospheric Chemistry and Physics, 1551-1564.

Piguet, B. and Méquignon, A., 2000. Contenu des fichiers ASCII-1Hz des données du Piper-Aztec durant les campagnes Pre-ESCOMPTE et AMPADI: Note Météo-France CNRM/GMEI/TRAMM in ESCOMPTE database (http://medias.obs-mip.fr/escompte/documents/index).

Puygrenier, V., Lohou, F., Campistron, B., Saïd, F., Pigeon, G., Benech, B., Serça, D., 2004. Investigation on the fine structure of sea breeze during ESCOMPTE experiment. Atmos. Res. 74, 329-353 (this issue).

Quante, M., Brown, P.R.A., Baumann, R., Guillemet, B., Hignett, P., 1996. Three-aircraft intercomparison of dynamical, thermodynamical Measurements during the Pre-EUCREX campaign. Beitraege zur Physik der Atmosphaere, 129-146.

Shetter, R.E., et al., 2003. Photolysis frequency of NO2: measurement and modeling during the International Photolysis Frequency Measurement and Modeling Intercomparison (IPMMI). Journal of Geophysical Research 108 (D16), 8544-8568.

Ström, J., Busen, R., Quante, B., Guillemet, B., Brown, P.R.A., Heintzenberg, J., 1994. Pre-EUCREX intercomparison of airborne humidity measuring instruments. Journal of Atmospheric and Oceanic Technology 11, 1392-1399.

Vörsmann, P., 1985. Ein beitrag zur bordautonomen windmessung: Dissertation, Fakultät fûr maschinbau und electronik, Technische Universität Braunschweig, (140 pp.).

Wieser, A., 2004. Messung turbulenter Spurengasfluesse vom Flugzeug aus: Dissertation an der Fakultät für Physik der Universität Karlsruhe. (212 pp.). 